\title{
Analytical Modelling of Three-Dimensional Squeezing Nanofluid Flow in a Rotating Channel on a Lower Stretching Porous Wall
}

\author{
Navid Freidoonimehr, ${ }^{1}$ Behnam Rostami, ${ }^{1}$ \\ Mohammad Mehdi Rashidi, ${ }^{2}$ and Ebrahim Momoniat $^{3}$ \\ ${ }^{1}$ Young Researchers \& Elite Club, Islamic Azad University, Hamedan Branch, Hamedan 65181 15743, Iran \\ ${ }^{2}$ Mechanical Engineering Department, Engineering Faculty of Bu-Ali Sina University, Hamedan 65178 38695, Iran \\ ${ }^{3}$ Centre for Differential Equations, Continuum Mechanics and Applications, School of Computational and Applied Mathematics, \\ University of the Witwatersrand, Private Bag 3, Johannesburg 2050, South Africa
}

Correspondence should be addressed to Mohammad Mehdi Rashidi; mm_rashidi@yahoo.com

Received 3 July 2014; Accepted 30 July 2014; Published 17 August 2014

Academic Editor: Sandile Motsa

Copyright (C) 2014 Navid Freidoonimehr et al. This is an open access article distributed under the Creative Commons Attribution License, which permits unrestricted use, distribution, and reproduction in any medium, provided the original work is properly cited.

A coupled system of nonlinear ordinary differential equations that models the three-dimensional flow of a nanofluid in a rotating channel on a lower permeable stretching porous wall is derived. The mathematical equations are derived from the NavierStokes equations where the governing equations are normalized by suitable similarity transformations. The fluid in the rotating channel is water that contains different nanoparticles: silver, copper, copper oxide, titanium oxide, and aluminum oxide. The differential transform method (DTM) is employed to solve the coupled system of nonlinear ordinary differential equations. The effects of the following physical parameters on the flow are investigated: characteristic parameter of the flow, rotation parameter, the magnetic parameter, nanoparticle volume fraction, the suction parameter, and different types of nanoparticles. Results are illustrated graphically and discussed in detail.

\section{Introduction}

Due to the vast number of applications in chemical as well as mechanical engineering processes such as the manufacture of thin plastic sheets, insulating materials, paper fabrication, and other various processes, this paper pays particular attention to the investigation of rotating flow over stretching surfaces [1].

Sakiadis $[2,3]$ initiated the study of boundary-layer flow over a continuous solid surface that moves with constant speed. Considering the effect of suction/injection, Erickson et al. [4] studied heat and mass transfer over a moving surface with constant surface velocity and temperature. Tsou et al. [5] studied heat transfer effects of a moving solid surface with constant velocity and temperature. Crane [6] investigated the two-dimensional flow of a viscous fluid over a stretching wall. Andersson [7] investigated MHD effects on boundary-layer flow of a viscoelastic fluid flow past a stretching sheet. Prasad et al. [8] employed a fourth order Runge-Kutta integration scheme to investigate the effect of variable fluid viscosity, magnetic parameter, Prandtl number, variable thermal conductivity, heat source/sink parameter, and thermal radiation parameter on MHD fluid flow over a stretching sheet. The generalized three-dimensional flow and heat transfer over a stretching sheet and in a channel bounded by the lower stretching plate and upper permeable wall were studied by Mehmood and Ali $[9,10]$. Three-dimensional flow in a channel with a stretching wall was investigated by Borkakoti and Bharali [11]. Munawar et al. [12] analyzed the slip effect on the flow in a channel bounded by two stretching disks analytically.

Flow squeezed by two parallel plates has been investigated by various researchers. Chamkha et al. [13] determined an analytical solution for the problem of fully developed free 
convective flow of a micropolar fluid between two vertical parallel plates. Bhargava et al. [14] investigated the fully developed flow and heat transfer of an electrically conducting micropolar fluid (a strong cross magnetic field) between two parallel and porous plates in which the temperature has been considered to be dependent on the heat source, including the effect of frictional heating. The quasilinearization method is used to solve the governing system of ordinary differential equations. Ariel [15] presented solutions for two problems of laminar forced convection of a second-grade (viscoelastic) fluid through two parallel porous walls considering rectangular and cylindrical geometries. Applying similarity transformations to the governing nonlinear partial differential equations, Hayat and Abbas [16] derived nonlinear ordinary differential equations and studied the two-dimensional boundary-layer flow of an upper-convected Maxwell fluid in a channel with chemical reaction. Domairry and Aziz [17] obtained an analytic solution for unsteady MHD squeezing flow with suction and injection effects by the use of homotopy perturbation method.

To the best of authors' knowledge, Choi and Eastman [18] were probably the first researchers who employed a mixture of nanoparticles and base fluid and called this mixture a "nanofluid." A wide range of review papers have been published on nanofluids in recent years. Xuan and $\mathrm{Li}$ [19] considered the Reynolds number and volume fraction of nanoparticle influences in turbulent flows for nanofluids in tubes experimentally. Bachok et al. [20] employed a numerical, Keller-Box technique for steady nanofluid flow over a porous rotating disk. Khan and Pop [21] studied laminar flow for a nanofluid across a stretching flat surface using an implicit finite difference method. Abolbashari et al. [22] employed HAM to study the entropy analysis in an unsteady MHD nanofluid regime adjacent to an accelerating stretching permeable surface. Beg et al. [23] presented a comparative numerical solution for both single- and two-phase models for bionanofluid transport phenomena. Rashidi et al. [24] compared the two phase and single phase of heat transfer and flow field of copper-water nanofluid in a wavy channel numerically. Abu-Nada et al. [25] illustrated the impacts of variable properties in natural convection nanofluid flow. Rashidi et al. [26] showed how the second law of thermodynamics can be applied to MHD incompressible nanofluid flow over a porous rotating disk. The stagnation flow for a nanofluid over a stretching sheet was studied by Mustafa et al. [27] analytically. The interested reader is referred to the following papers for further reading on the application of nanoparticles in fluid flow [28-30].

In this paper we derive a coupled system of nonlinear ordinary differential equations to model the threedimensional flow of a nanofluid in a rotating channel on a lower permeable stretching wall. The resulting system of equations is solved using the differential transform method (DTM) [31, 32]. The DTM method has been applied successfully to solve nonlinear differential equations without requiring linearization or discretization [33]. The present DTM code is benchmarked with numerical results based on a shooting technique and previously published results.

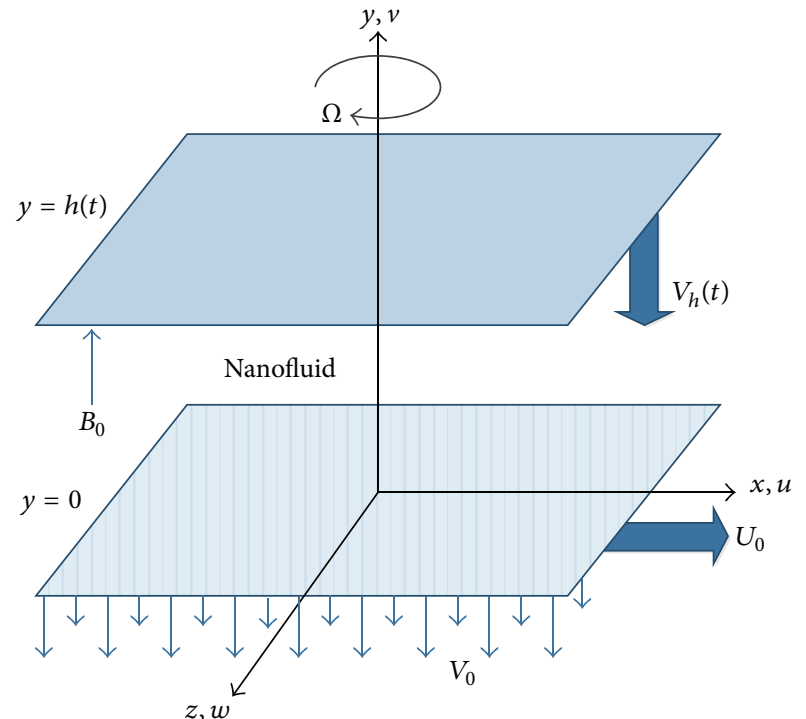

FIGURE 1: Schematic diagram of the flow configuration and the coordinate system for the considered flow.

The DTM method shows excellent correlation with results obtained using these other methods.

The paper is divided up as follows: in Section 2, the problem is formulated and a coupled system of nonlinear ordinary differential equations is derived. The DTM method is applied to solve the resulting system of nonlinear ordinary differential equations in Section 3. Results are discussed in Section 4. Concluding remarks are made in Section 5.

\section{Mathematical Formulation of the Problem}

Consider unsteady 3D rotating nanofluid flow of an incompressible electrically conducting viscous fluid between two infinite horizontal plane walls. The lower plane is placed at $y=0$ and is stretched with a time-dependent velocity $U_{0}(t)=$ $a x /(1-\gamma t)$ in $x$-direction. The upper plane is also placed at a variable distance $h(t)=\sqrt{\nu_{f}(1-\gamma t) / a}$ and the fluid is squeezed with a time-dependent velocity $V_{h}=d h / d t$ in the negative $y$-direction. The fluid and the channel are rotating around $y$-axis with an angular velocity $\Omega=\omega \widehat{J} /(1-\gamma t)$ and also the lower plate intakes the flow with the velocity $-V_{0} /(1-\gamma t)$. A magnetic field with density $B_{0} / \sqrt{(1-\gamma t)}$ is applied along the $y$-axis about the system which is rotating. These velocities and magnetic fields are introduced to obtain similarity solutions by reducing governing equations into ordinary differential equations (ODEs). The physical model of the considered problem along with the coordinate system is illustrated in Figure 1. The governing equations of continuity and momentum of nanofluid flow in a rotating frame of reference are given as $[34,35]$

$$
\begin{gathered}
\nabla \cdot \mathbf{V}=0 \\
\rho_{\mathrm{nf}}\left[\frac{\partial \mathbf{V}}{\partial t}+(\mathbf{V} \cdot \nabla) \mathbf{V}+2 \mathbf{\Omega} \times \mathbf{V}\right]=\nabla \cdot \mathbf{T}+\mathbf{J} \times \mathbf{B}
\end{gathered}
$$


TABLE 1: Thermophysical properties of the base fluid and different nanoparticles [39].

\begin{tabular}{lcccccc}
\hline Physical properties & Fluid phase (water) & $\mathrm{Cu}$ & $\mathrm{CuO}$ & $\mathrm{Ag}$ & $\mathrm{Al}_{2} \mathrm{O}_{3}$ & $\mathrm{TiO}_{2}$ \\
\hline$\rho\left(\mathrm{kg} / \mathrm{m}^{3}\right)$ & 997.1 & 8933 & 6320 & 10500 & 3970 & 4250 \\
\hline
\end{tabular}

where $\mathbf{T}$ is the Cauchy stress tensor, $\mathbf{J}$ the magnetic flux, and $\mathbf{B}$ the current density. The above governing equations can be also described by the following set of Navier-Stokes equations $[36,37]$ :

$$
\begin{gathered}
\frac{\partial u}{\partial x}+\frac{\partial v}{\partial y}=0 \\
\frac{\partial u}{\partial t}+u \frac{\partial u}{\partial x}+v \frac{\partial u}{\partial y}+2 \frac{\omega}{1-\gamma t} w \\
=-\frac{1}{\rho_{\mathrm{nf}}} \frac{\partial p}{\partial x}+v_{\mathrm{nf}}\left[\frac{\partial^{2} u}{\partial x^{2}}+\frac{\partial^{2} u}{\partial y^{2}}\right]-\frac{\sigma B_{0}^{2}}{\rho_{\mathrm{nf}}(1-\gamma t)} u, \\
\frac{\partial v}{\partial t}+u \frac{\partial v}{\partial x}+v \frac{\partial v}{\partial y}=-\frac{1}{\rho_{\mathrm{nf}}} \frac{\partial p}{\partial y}+v_{\mathrm{nf}}\left[\frac{\partial^{2} v}{\partial x^{2}}+\frac{\partial^{2} v}{\partial y^{2}}\right] \\
\frac{\partial w}{\partial t}+u \frac{\partial w}{\partial x}+v \frac{\partial w}{\partial y}-2 \frac{\omega}{1-\gamma t} u \\
=v_{\mathrm{nf}}\left[\frac{\partial^{2} w}{\partial x^{2}}+\frac{\partial^{2} w}{\partial y^{2}}\right]-\frac{\sigma B_{0}^{2}}{\rho_{\mathrm{nf}}(1-\gamma t)} w,
\end{gathered}
$$

where $\rho_{\mathrm{nf}}$ is the nanofluid density, $\nu_{\mathrm{nf}}\left(=\mu_{\mathrm{nf}} / \rho_{\mathrm{nf}}\right)$ is the nanofluid kinematic viscosity, where $\mu_{\mathrm{nf}}$ has been proposed by Brinkman [38], $\sigma$ is the electrical conductivity, $B_{0}$ is the magnetic field, and $\gamma$ is the characteristic parameter with dimension of (time) ${ }^{-1}$ and $\gamma t<1$. The above nanofluid constants are defined as follows:

$$
\mu_{\mathrm{nf}}=\frac{\mu_{f}}{(1-\varphi)^{2.5}}, \quad \rho_{\mathrm{nf}}=(1-\varphi) \rho_{f}+\varphi \rho_{s}
$$

where $\mu_{f}$ is the viscosity of the fluid fraction, $\varphi$ is the nanoparticle volume fraction, and $\rho_{f}$ and $\rho_{s}$ are the densities of the fluid and of the solid fractions, respectively. The thermophysical properties of the base fluid (water) and different nanoparticles are given in Table 1 [39]. The appropriate boundary conditions are introduced as follows:

$$
\begin{gathered}
u(x, y, t)=U_{0}=\frac{a x}{1-\gamma t}, \\
v(x, y, t)=-\frac{V_{0}}{1-\gamma t}, \\
w(x, y, t)=0, \\
\left.\begin{array}{c}
u(x, y, t)=0, \\
v(x, y, t)=V_{h}=\frac{d h}{d t}=\frac{-\gamma}{2} \sqrt{\frac{v_{f}}{a(1-\gamma t)}}, \\
w(x, y, t)=0,
\end{array}\right\} \quad \text { at } y=0,
\end{gathered}
$$

where $a$ is the stretching rate of the lower plate. The following appropriate similarity transformations are employed to convert the above governing equations (2)-(4) into a system of ordinary differential equations in terms of a stream function $\psi$ :

$$
\begin{gathered}
\psi=\sqrt{\frac{a \nu_{f}}{1-\gamma t}} x f(\eta), \quad \eta=\frac{y}{h(t)}, \\
u=\frac{\partial \psi}{\partial y}=U_{0} f^{\prime}(\eta), \quad v=-\frac{\partial \psi}{\partial x}=-\sqrt{\frac{a \nu_{f}}{1-\gamma t}} f(\eta), \\
w=U_{0} g(\eta) .
\end{gathered}
$$

Substituting the similarity transformations (5) and (6) into (2)-(4), we obtain the following system of nonlinear ordinary differential equations:

$$
\begin{gathered}
f^{\prime \prime \prime}+\frac{v_{f}}{v_{\mathrm{nf}}}\left(f f^{\prime \prime}-\left(f^{\prime}\right)^{2}-\beta\left(f^{\prime}+\frac{\eta}{2} f^{\prime \prime}\right)\right. \\
\left.\quad-2 \Omega g-\frac{1}{\rho_{\mathrm{nf}} / \rho_{f}} M^{2} f^{\prime}\right)=\frac{(1-\gamma t)^{2} v_{f}}{\rho_{\mathrm{nf}} a^{2} x \nu_{\mathrm{nf}}} \frac{\partial p}{\partial x}, \\
-f^{\prime \prime}+\frac{v_{f}}{v_{\mathrm{nf}}}\left(-f f^{\prime}+\frac{\beta}{2}\left(f+\eta f^{\prime}\right)\right)=\frac{1-\gamma t}{\rho_{\mathrm{nf}} a \nu_{\mathrm{nf}}} \frac{\partial p}{\partial \eta} \\
g^{\prime \prime}+\frac{v_{f}}{v_{\mathrm{nf}}}\left(f g^{\prime}-f^{\prime} g-\beta\left(g+\frac{\eta}{2} g^{\prime}\right)+2 \Omega f^{\prime}\right) \\
-\frac{1}{\mu_{\mathrm{nf}} / \mu_{f}} M^{2} g=0,
\end{gathered}
$$

where $\beta=\gamma / a$ is the characteristic parameter of the flow, $\Omega=\omega / a$ is the rotation parameter, $M^{2}=\sigma B_{0}^{2} / \rho_{f} a$ is the magnetic parameter, and prime denotes differentiation with respect to $\eta$. In order to squeeze the flow, we take $\beta>0$, for which the upper plate moves downward with velocity $V_{h}<0$. For $\beta<0$ the upper plate moves apart with respect to the plane $y=0$ and $\beta=0$ corresponds to the steady state case of the considered problem or stationary upper plate. In order to reduce the number of independent variables and to retain the similarity solution, (7) are simplified by cross differentiation and thus we obtain the following system of differential equations:

$$
\begin{aligned}
f^{i v} & -\left(1-\varphi+\varphi\left(\rho_{s} / \rho_{f}\right)\right)(1-\varphi)^{2.5} \\
& \times\left(f^{\prime} f^{\prime \prime}-f f^{\prime \prime \prime}+2 \Omega g^{\prime}+\frac{\beta}{2}\left(3 f^{\prime \prime}+\eta f^{\prime \prime \prime}\right)\right) \\
& -(1-\varphi)^{2.5} M^{2} f^{\prime \prime}=0, \\
g^{\prime \prime} & +\left(1-\varphi+\varphi\left(\rho_{s} / \rho_{f}\right)\right)(1-\varphi)^{2.5} \\
& \times\left(f g^{\prime}-f^{\prime} g-\beta\left(g+\frac{\eta}{2} g^{\prime}\right)+2 \Omega f^{\prime}\right) \\
& -(1-\varphi)^{2.5} M^{2} g=0 .
\end{aligned}
$$


The transformed boundary conditions take the form

$$
\begin{array}{lll}
f(0)=w_{0}, & f^{\prime}(0)=1, & g(0)=0, \\
f(1)=\frac{\beta}{2}, & f^{\prime}(1)=0, & g(1)=0,
\end{array}
$$

where $w_{0}=V_{0} / a h$ is the suction parameter.

In this problem, the physical quantity of interest is the skin friction coefficients $C_{f}$ along the stretching wall at the lower and upper walls which are defined as [40]

$$
\begin{gathered}
C_{f, \text { lower }}=\frac{\mu_{\mathrm{nf}}(\partial u / \partial y)_{y=0}}{\rho_{\mathrm{nf}} U_{0}^{2}}, \\
C_{f \text {,upper }}=\frac{\mu_{\mathrm{nf}}(\partial u / \partial y)_{y=h(t)}}{\rho_{\mathrm{nf}} U_{0}^{2}} .
\end{gathered}
$$

Substituting (6) into (11) we obtain

$$
\begin{aligned}
& \bar{C}_{f, \text { lower }}=C_{f, \text { lower }} \operatorname{Re}_{x}=\frac{f^{\prime \prime}(0)}{\left(1-\varphi+\varphi\left(\rho_{s} / \rho_{f}\right)\right)(1-\varphi)^{2.5}}, \\
& \bar{C}_{f, \text { upper }}=C_{f, \text { upper }} \operatorname{Re}_{x}=\frac{f^{\prime \prime}(1)}{\left(1-\varphi+\varphi\left(\rho_{s} / \rho_{f}\right)\right)(1-\varphi)^{2.5}},
\end{aligned}
$$

where $\operatorname{Re}_{x}=\rho_{f} U_{0} h / \mu_{f}$ is the local Reynolds number.

In this section we have derived the coupled system of nonlinear ordinary differential equations (9) to model the three-dimensional flow of a nanofluid in a rotating channel on a lower permeable stretching wall. We next apply the DTM to solve the coupled system.

\section{Analytical Approximation by Means of DTM}

Taking the differential transform of (9), one can obtain (for more details, see $[41,42]$ )

$$
\begin{aligned}
& (k+1)(k+2)(k+3)(k+4) f(k+4) \\
& -(1-\varphi)^{2.5} M^{2}(k+1)(k+2) f(k+2) \\
& -\left(1-\varphi+\varphi\left(\frac{\rho_{s}}{\rho_{f}}\right)\right)(1-\varphi)^{2.5}
\end{aligned}
$$

$$
\begin{aligned}
& \times\left(\sum_{r=0}^{k}((k-r+1)(k-r+2)(r+1) f(r+1)\right. \\
& \times f(k-r+2)-(k-r+1)(k-r+2) \\
& \times(k-r+3) f(r) f(k-r+3)) \\
& +\frac{\beta}{2}(3(k+1)(k+2) f(k+2) \\
& \left.+\sum_{r=0}^{k}\left(\begin{array}{c}
(k-r+1)(k-r+2) \\
(k-r+3) \delta(r) f(k-r+3)
\end{array}\right)\right) \\
& +2 \Omega(k+1) g(k+1))=0 \\
& (k+1)(k+2) g(k+2)-(1-\varphi)^{2.5} M^{2} g(k) \\
& +\left(1-\varphi+\varphi\left(\frac{\rho_{s}}{\rho_{f}}\right)\right)(1-\varphi)^{2.5}
\end{aligned}
$$

$$
\begin{aligned}
& \times\left(\sum_{r=0}^{k}((k-r+1) f(r) g(k-r+1)\right. \\
& \quad-(k-r+1) g(r) f(k-r+1))) \\
& +2 \Omega(k+1) f(k+1) \\
& -\beta\left(g(k)+\left(\frac{1}{2}\right)\right. \\
& \left.\left.\quad \times \sum_{r=0}^{k}((k-r+1) \delta(r) g(k-r+1))\right)\right)=0
\end{aligned}
$$

where $f(k)$ and $g(k)$ are differential transforms of $f(\eta)$ and $g(\eta)$ given by

$$
\begin{gathered}
f(\eta)=\sum_{k=0}^{\infty} f(k) \eta^{k}, \\
g(\eta)=\sum_{k=0}^{\infty} g(k) \eta^{k}, \\
f(0)=w_{0}, \quad f(1)=1, \quad f(2)=\alpha, \\
f(3)=\delta, \quad g(0)=0, \quad g(1)=\varepsilon,
\end{gathered}
$$

where (16) is the transformed boundary conditions and $\alpha, \delta$, and $\varepsilon$ are constants. By substituting (16) into (13), using recursion, and then substituting them in (14)-(15), we obtain the values of $f(\eta)$ and $g(\eta)$ given by 


$$
\begin{aligned}
& f(\eta)=w_{0}+\eta+\alpha \eta^{2}+\delta \eta^{3}+\frac{1}{24} \\
& \times\left(\begin{array}{c}
2 M^{2}(1-\varphi)^{2.5} \alpha+(1-\varphi)^{2.5}\left(1-\varphi+\frac{\rho_{s}}{\rho_{f}} \varphi\right) \\
\left(2 \alpha+3 \alpha \beta-6 w_{0} \delta+2 \Omega \varepsilon\right)
\end{array}\right) \\
& \times \eta^{4}+\cdots \\
& g(\eta)=\eta \varepsilon+\frac{1}{2}(1-\varphi)^{2.5}\left(1-\varphi+\left(\frac{\rho_{s}}{\rho_{f}}\right) \varphi\right) \\
& \times\left(-2 \Omega-w_{0} \varepsilon\right) \eta^{2}+\frac{1}{6} \\
& \times\left(\begin{array}{c}
M^{2}(1-\varphi)^{2.5} \varepsilon+(1-\varphi)^{2.5}\left(1-\varphi+\left(\frac{\rho_{s}}{\rho_{f}}\right) \varphi\right) \\
\left(-4 \Omega \alpha+\frac{3 \beta \varepsilon}{2}-(1-\varphi)^{2.5}\left(1-\varphi+\left(\frac{\rho_{s}}{\rho_{f}}\right) \varphi\right) w_{0}\left(-2 \Omega-w_{0} \varepsilon\right)\right)
\end{array}\right) \\
& \times \eta^{3}+\frac{1}{12} \\
& \times\left(\frac{1}{2} M^{2}(1-\varphi)^{5}\left(1-\varphi+\left(\frac{\rho_{s}}{\rho_{f}}\right) \varphi\right)\left(-2 \Omega-w_{0} \varepsilon\right)\right. \\
& +(1-\varphi)^{2.5}\left(1-\varphi+\left(\frac{\rho_{s}}{\rho_{f}}\right) \varphi\right) \\
& \times\left(-6 \Omega \delta-\frac{1}{2}(1-\varphi)^{2.5}\left(1-\varphi+\left(\frac{\rho_{s}}{\rho_{f}}\right) \varphi\right)\left(-2 \Omega-w_{0} \varepsilon\right)\right. \\
& +\beta(1-\varphi)^{2.5}\left(1-\varphi+\left(\frac{\rho_{s}}{\rho_{f}}\right) \varphi\right)\left(-2 \Omega-w_{0} \varepsilon\right)+\alpha \varepsilon-\frac{1}{2} w_{0} \\
& \left.\times\left(\begin{array}{c}
M^{2}(1-\varphi)^{2.5} \varepsilon+(1-\varphi)^{2.5}\left(1-\varphi+\left(\frac{\rho_{s}}{\rho_{f}}\right) \varphi\right) \\
-4 \Omega \alpha+\frac{3 \beta \varepsilon}{2} \\
-(1-\varphi)^{2.5}\left(1-\varphi+\left(\frac{\rho_{s}}{\rho_{f}}\right)^{2} \varphi\right) w_{0}\left(-2 \Omega-w_{0} \varepsilon\right)
\end{array}\right)\right) \\
& \times \eta^{4}+\cdots
\end{aligned}
$$

The constants $\alpha, \delta$, and $\varepsilon$ can be determined by applying the remaining boundary conditions to (17). The number of required terms is determined by the convergence of the numerical values to one's desired accuracy. We obtain the approximants using the computational software MATHEMATICA. The effect of different orders of the DTM solution 


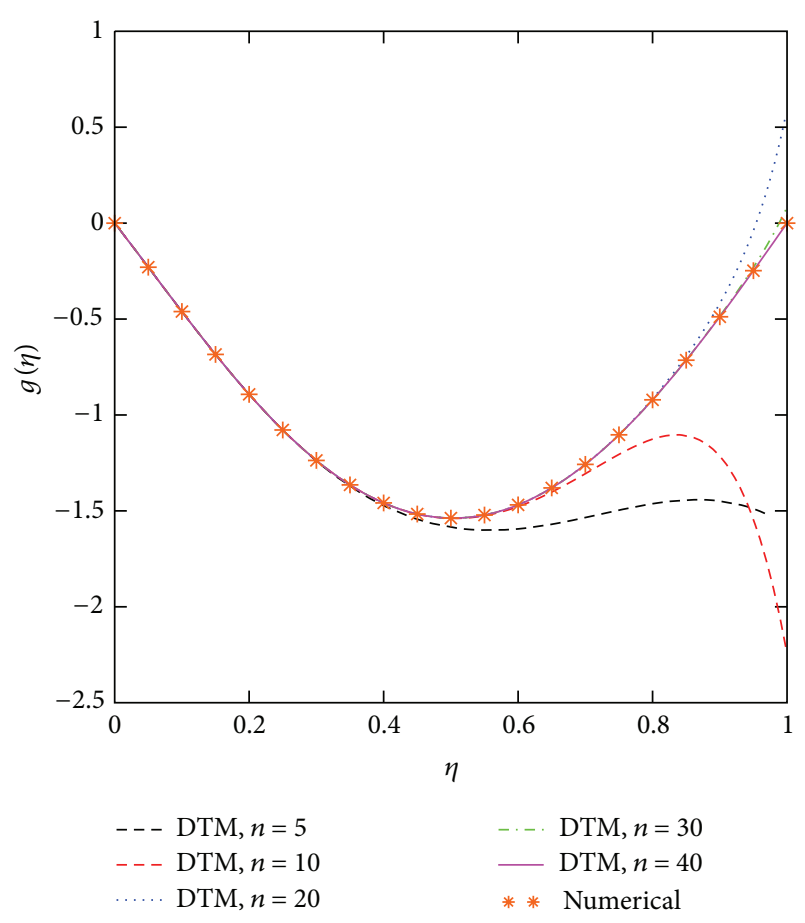

FIgURE 2: The obtained results of transverse velocity of $g(\eta)$ for different orders of DTM solution in comparison with the numerical solution when $\beta=-1, \Omega=3, M=2, \varphi=0.1$, and $w_{0}=0.5$.

on the convergence radius of the transverse velocity of $g(\eta)$ is displayed in Figure 2.

In order to highlight the validity of the presented DTM solution, we compare some of our results with the obtained HAM results of [1]. A very good validation of the present analytical results has been achieved with the previously published study as shown in Table 2 .

\section{Results and Discussion}

In the previous section the nonlinear ordinary differential equations (9) are solved subject to the boundary conditions (10) via the DTM method for values of the five key parameters: characteristic parameter of the flow $(\beta)$, rotation parameter $(\Omega)$, the magnetic parameter $(M)$, nanoparticle volume fraction $(\varphi)$, the suction parameter $\left(w_{0}\right)$, and different nanoparticles on the different velocity components. It should be stated that the copper nanoparticle is used in all of the cases in this section except for those figures which focus on the influences of the types of applied nanoparticles on the velocity component profiles. In addition, we assume that the values of the volume fraction parameter $\varphi$ vary from 0 (regular Newtonian fluid) to 0.2. Representative values are employed to simulate the physically realistic flows. Tables 2 and 3 display the comparison between the DTM and numerical solution results based on a shooting technique for the shear stresses at lower and upper walls for different values of $w_{0}$ and $\beta$.

The influence of nanoparticle volume fraction $(\varphi)$ on the normal, axial, and transverse velocity components is shown in Figures 3, 4, and 5. The normal velocity component

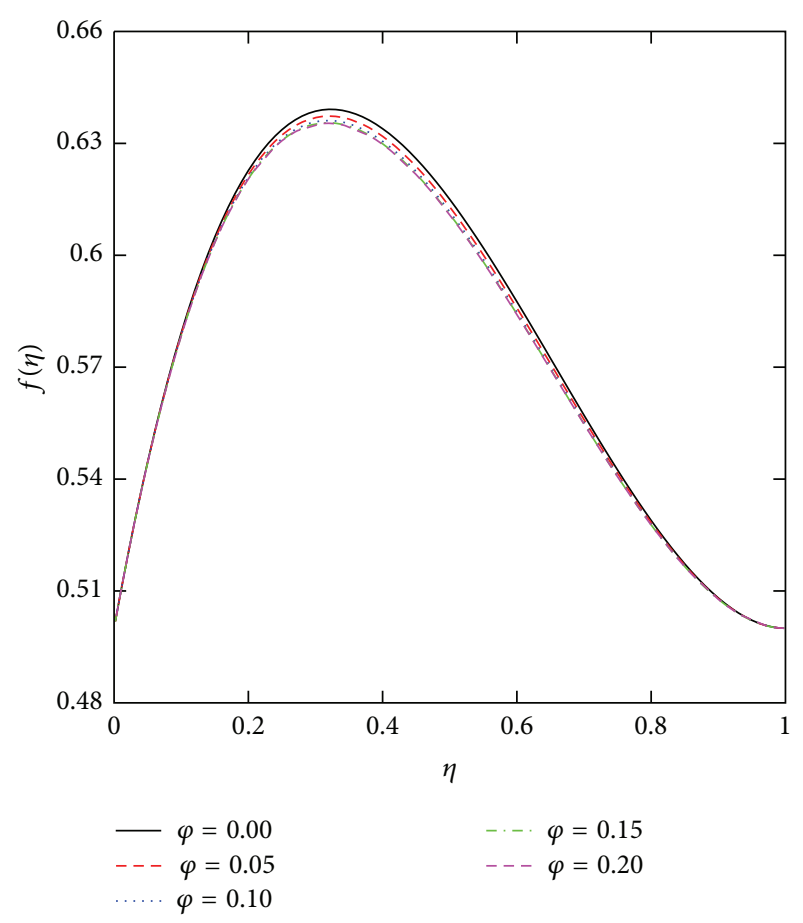

FIGURE 3: Effect of $\varphi$ on the velocity component of $f(\eta)$ when $\beta=$ $\Omega=1$ and $M=w_{0}=0.5$.

reduces for higher values of the nanoparticle volume fraction. The axial velocity profile decreases with the increase in nanoparticle volume fraction in the lower half channel while in the upper half of the channel, $f^{\prime}(\eta)$ enhances with the increase in $\varphi$. In addition, transverse velocity profile increases near the lower surface for the large value of nanoparticle volume fraction, but the adverse trend happens on the other side (in the center and the upper half of the channel).

The effects of the characteristic parameter of flow $(\beta)$ on the velocity component $f(\eta)$ are plotted in Figure 6. As one can see, with the increase in $\beta$, the velocity profile $f(\eta)$ augments in the vicinity of the upper plane. It can be easily understood that it accumulates the squeezing effects on the flow. In Figure 7, the effect of characteristic parameter of the flow on the velocity component, parallel to $x$-axis, $f^{\prime}(\eta)$, is depicted and it is clearly obvious that the velocity increases with the increase in the value of $\beta$. It should be noted that the higher values of $\beta$ amortize the reverse flow, but the negative values of $\beta$ support the reverse flow because of the squeezing and extricating effects of the upper wall. The same trend can be observed for transverse velocity component. Figure 8 shows that the transverse velocity component $g(\eta)$ increases as $\beta$ increases.

Figure 9 shows the effect of rotation parameter $(\Omega)$ on the normal velocity component $(f(\eta))$. The normal velocity component reduces for large values of the rotation parameter. The effect of the rotation parameter on the axial velocity component $\left(f^{\prime}(\eta)\right)$ is presented in Figure 10. The results show that in the lower half channel, the velocity component parallel to $x$-direction decreases with the increase in rotation parameter, while in the upper half of the channel, $f^{\prime}(\eta)$ 
TABLE 2: Comparison results of shear stresses at lower and upper walls for different values of $w_{0}$ when $\beta=\Omega=2, M=0.5$, and $\varphi=0$.

\begin{tabular}{|c|c|c|c|c|}
\hline \multirow{2}{*}{$w_{0}$} & \multicolumn{2}{|c|}{$f^{\prime \prime}(0)$} & \multicolumn{2}{|c|}{$f^{\prime \prime}(1)$} \\
\hline & DTM Result & HAM result of [1] & DTM result & HAM result of [1] \\
\hline 0.0 & +2.00373789 & +2.0037379 & -4.58270559 & -4.5827056 \\
\hline 0.3 & +0.06127071 & +0.0612707 & -2.62278886 & -2.6227888 \\
\hline 0.6 & -1.98233944 & -1.9823394 & -0.73129902 & -0.7312990 \\
\hline 0.9 & -4.13494482 & -4.1349448 & +1.09241241 & +1.0924124 \\
\hline 1.2 & -6.40476369 & -6.4047636 & +2.84916544 & +2.8491655 \\
\hline
\end{tabular}

TABLE 3: Comparison results of shear stresses at lower and upper walls or different values of $w_{0}$ and $\beta$ when $\Omega=1, M=0.5$, and $\varphi=0.1$.

\begin{tabular}{|c|c|c|c|c|c|}
\hline \multirow{2}{*}{$w_{0}$} & \multirow{2}{*}{$\beta$} & \multicolumn{2}{|c|}{$\bar{C}_{f, \text { lower }}$} & \multicolumn{2}{|c|}{$\bar{C}_{f \text {,upper }}$} \\
\hline & & DTM result & Numerical result & DTM result & Numerical result \\
\hline \multirow{7}{*}{0.0} & -3.0 & -8.52098772 & -8.52098769 & +7.53714763 & +7.53714759 \\
\hline & -2.0 & -6.76815369 & -6.76815367 & +5.55472891 & +5.55472890 \\
\hline & -1.0 & -4.97050617 & -4.97050616 & +3.54801649 & +3.54801648 \\
\hline & 0.0 & -3.01634611 & -3.01634612 & +1.39835301 & +1.39835302 \\
\hline & +1.0 & -0.89270759 & -0.89270759 & -0.90954349 & -0.90954349 \\
\hline & +2.0 & +1.39749899 & +1.39749899 & -3.37418335 & -3.37418335 \\
\hline & +3.0 & +3.84773079 & +3.84773079 & -5.99011133 & -5.99011133 \\
\hline \multirow{7}{*}{0.5} & -3.0 & -11.7761059 & -11.7761055 & +9.47810573 & +9.47810571 \\
\hline & -2.0 & -9.51967384 & -9.51967382 & +7.18294804 & +7.18294803 \\
\hline & -1.0 & -7.59674602 & -7.59674601 & +5.33619342 & +5.33619342 \\
\hline & 0.0 & -5.56301306 & -5.56301307 & +3.38177815 & +3.38177815 \\
\hline & +1.0 & -3.37407009 & -3.37407009 & +1.26581626 & +1.26581626 \\
\hline & +2.0 & -1.02490197 & -1.02490197 & -1.01698614 & -1.01698614 \\
\hline & +3.0 & +1.48110397 & +1.48110397 & -3.46202219 & -3.46202219 \\
\hline \multirow{7}{*}{1.0} & -3.0 & -17.7188652 & -17.7188648 & +14.8771382 & +14.8771378 \\
\hline & -2.0 & -12.7797205 & -12.7797203 & +8.72969245 & +8.72969242 \\
\hline & -1.0 & -10.6266507 & -10.6266506 & +6.92986184 & +6.92986182 \\
\hline & 0.0 & -8.46845956 & -8.46845957 & +5.16113154 & +5.16113153 \\
\hline & +1.0 & -6.18186918 & -6.18186918 & +3.24194096 & +3.24194096 \\
\hline & +2.0 & -3.74763053 & -3.74763053 & +1.14862333 & +1.14862333 \\
\hline & +3.0 & -1.16400368 & -1.16400368 & -1.11763550 & -1.11763550 \\
\hline
\end{tabular}

increases with the increase in $\Omega$. This reverse trend occurs approximately in the center of the channel $(\eta \cong 0.4)$. The effect of rotation parameter $(\Omega)$ on the transverse velocity $g(\eta)$ is shown in Figure 11. It is clear that although the large rotation causes an increase in transverse velocity near lower surface, the adverse trend occurs on the other side. In the main nanoflow regime, two diverse trends can be noticed. In the lower half channel the transverse velocity increases, in the center and the upper half of the channel the transverse velocity decreases.

The effect of magnetic parameter $(M)$ on the normal, axial, and transverse velocity components can be observed in Figures 12-14. From Figure 12, it is seen that the velocity decreases as magnetic parameter increases because Lorentz force tends to decrease the velocity profile $f(\eta)$. In Figure 13, two different trends can be seen. In the lower half of the channel, the velocity component parallel to the $x$-direction decreases with the increase in the magnetic parameter, while in the upper half of the channel, $f^{\prime}(\eta)$ increases with the increase in $M$. This reverse trend occurs approximately in the center of the channel. The transverse velocity shows increasing behavior with the increase in magnetic parameter in all region of the channel (Figure 14).

The consequence of suction parameter $\left(w_{0}\right)$ on all the velocity profiles is illustrated in Figures 15, 16, and 17. Figure 15 depicts that as the suction parameter increases, the normal velocity component $(f(\eta))$ increases and the variation in the velocity profile confines in the vicinity of the upper plate. It is known that the large suction values cause $f^{\prime}(\eta)$ to decrease, which results in the occurrence of reverse flow. The reverse flow is more prominent near the upper plate rather than the lower plate. The reverse flow near the lower 
TABLE 4: Effect of nanoparticle volume fraction and nanoparticles material on the shear stresses at lower and upper walls when $\Omega=w_{0}=1$ and $\beta=M=0.5$.

\begin{tabular}{ccccccccccc}
\hline$\varphi$ & \multicolumn{2}{c}{$\mathrm{Ag}$} & \multicolumn{2}{c}{$\mathrm{Cu}$} & \multicolumn{2}{c}{$\mathrm{CuO}$} & $\mathrm{TiO}_{2}$ & \multicolumn{2}{c}{$\mathrm{Al}_{2} \mathrm{O}_{3}$} \\
& $\bar{C}_{f, \text { lower }}$ & $\bar{C}_{f \text {,upper }}$ & $\bar{C}_{f, \text { lower }}$ & $\bar{C}_{f, \text { upper }}$ & $\bar{C}_{f, \text { lower }}$ & $\bar{C}_{f \text {,upper }}$ & $\bar{C}_{f, \text { lower }}$ & $\bar{C}_{f \text {,upper }}$ & $\bar{C}_{f, \text { lower }}$ & $\bar{C}_{f, \text { upper }}$ \\
\hline 0.00 & -9.66151 & +5.987272 & -9.66151 & +5.987272 & -9.66151 & +5.987272 & -9.66151 & +5.987272 & -9.66151 & +5.987272 \\
0.05 & -7.72463 & +4.511947 & -8.08637 & +4.787926 & -8.79156 & +5.326106 & -9.46511 & +5.840246 & -9.5657 & +5.917038 \\
0.10 & -6.85916 & +3.85395 & -7.34313 & +4.222859 & -8.37683 & +5.011777 & -9.49215 & +5.863511 & -9.67086 & +5.999997 \\
0.15 & -6.45632 & +3.548727 & -7.00493 & +3.966591 & -8.24921 & +4.916332 & -9.71233 & +6.034163 & -9.95938 & +6.222928 \\
0.20 & -6.31569 & +3.44302 & -6.91686 & +3.900868 & -8.3391 & +4.986844 & -10.1216 & +6.349316 & -10.435 & +6.588886 \\
\hline
\end{tabular}

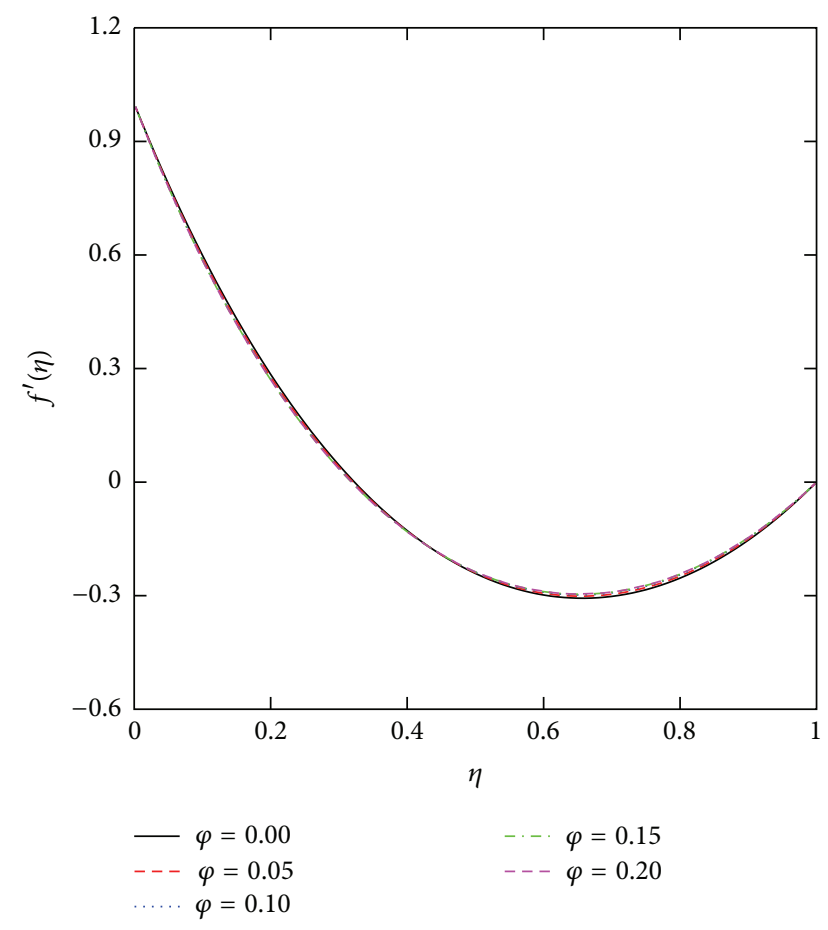

FIGURE 4: Effect of $\varphi$ on the velocity component of $f^{\prime}(\eta)$ when $\beta=$ $\Omega=1$ and $M=w_{0}=0.5$.

plate is produced by the adverse pressure gradient because the large amount of fluid particles escapes from the lower wall. Figure 17 shows the same behavior for the transverse velocity component $g(\eta)$.

Figures 18, 19, and 20 demonstrate the effect of different nanoparticle materials on the normal velocity component $(f(\eta))$, axial velocity component $\left(f^{\prime}(\eta)\right)$, and also the transverse velocity profile $(g(\eta))$. As the results show, the maximum amount of normal velocity component belongs to $\mathrm{Al}_{2} \mathrm{O}_{3}$ nanoparticle. Moreover, the effects of nanoparticle volume fraction and the types of nanoparticles on the shear stresses at lower and upper walls are depicted in Table 4.

\section{Conclusions}

In this paper, we have used DTM to solve a coupled system of nonlinear ordinary differential equations for threedimensional flow of a nanofluid in a rotating channel on

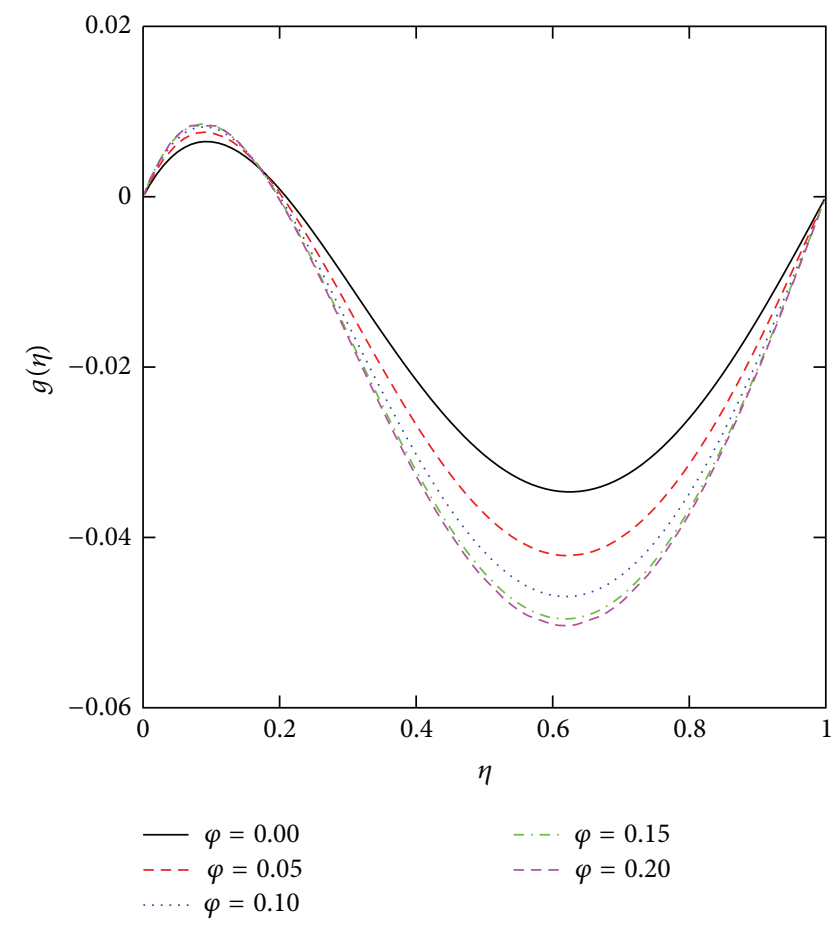

FIGURE 5: Effect of $\varphi$ on the velocity component of $g(\eta)$ when $\beta=$ $\Omega=1$ and $M=w_{0}=0.5$.

a lower permeable stretching wall. We have considered water the base fluid and four different types of nanoparticles, copper, copper oxide, aluminum oxide, and titanium dioxide have been examined in this simulation. The upper wall is moving along the direction normal to the surface with time dependent velocity. The transformed dimensionless equations have been formulated and solved with robust boundary conditions. Important physical parameters have been investigated graphically. These parameters include the flow parameter, the rotation parameter, the magnetic parameter, the nanoparticle volume fraction, the suction parameter, and also different types of nanoparticles. Results show that the vertical motion of the upper plate interrupts the velocity in the channel remarkably. The downward motion of the upper plate augments the forward flow, whereas the upward motion reverses the flow. 


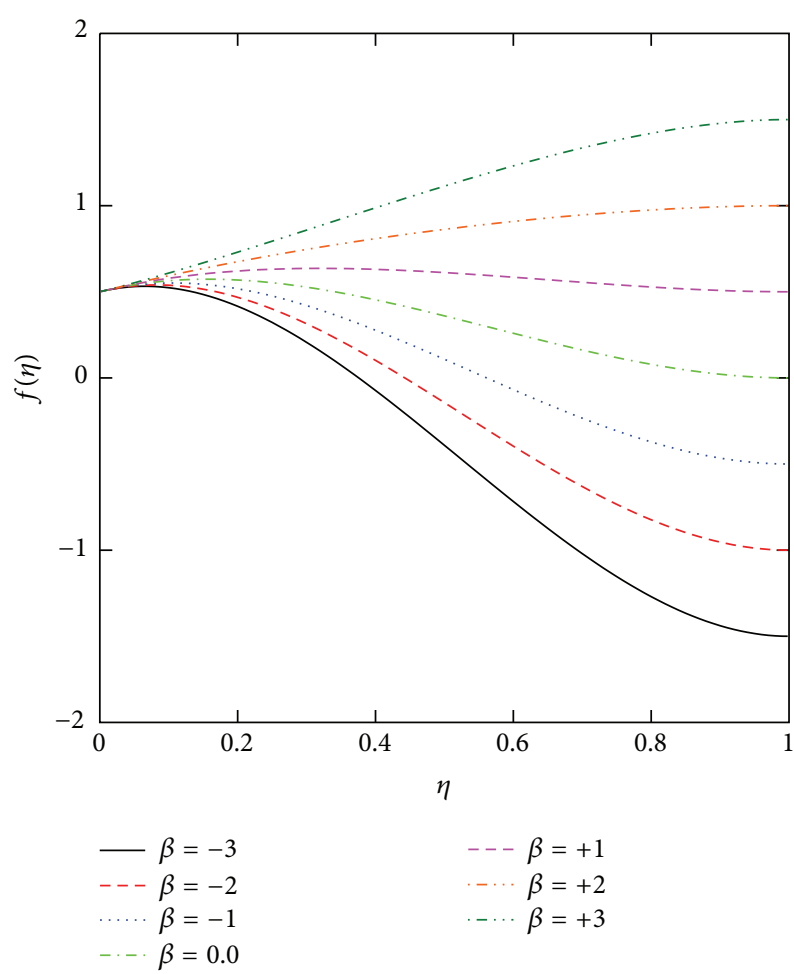

FigURE 6: Effect of $\beta$ on the velocity component of $f(\eta)$ when $\Omega=1$, $\varphi=0.1$, and $M=w_{0}=0.5$.

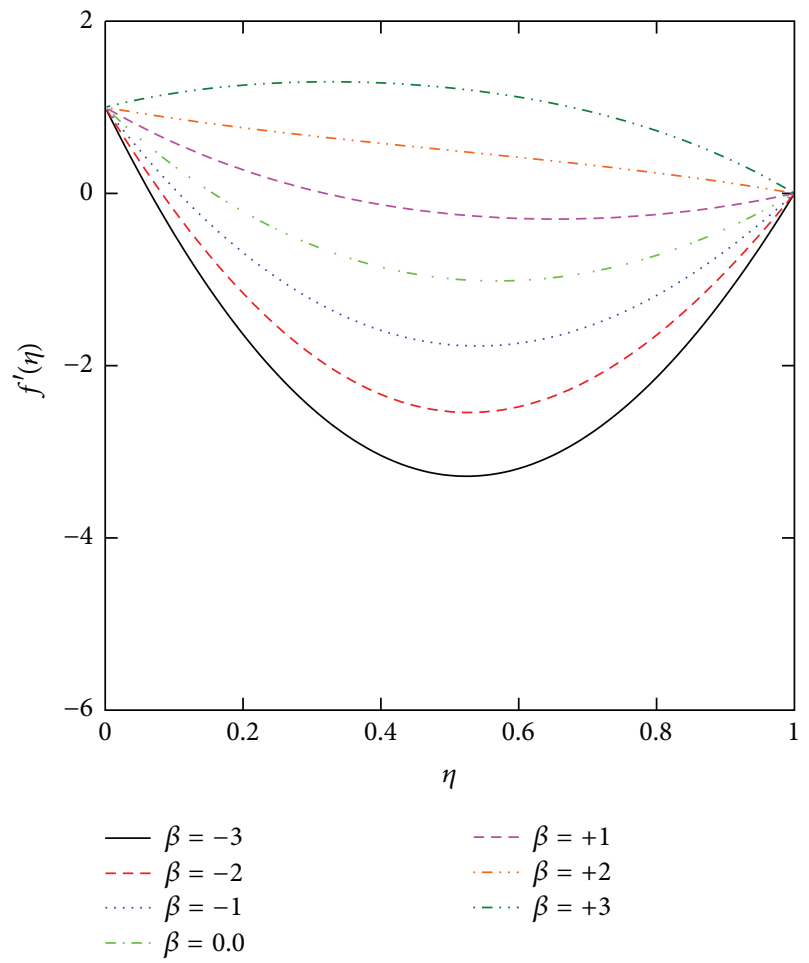

FigURE 7: Effect of $\beta$ on the velocity component of $f^{\prime}(\eta)$ when $\Omega=$ $1, \varphi=0.1$, and $M=w_{0}=0.5$.

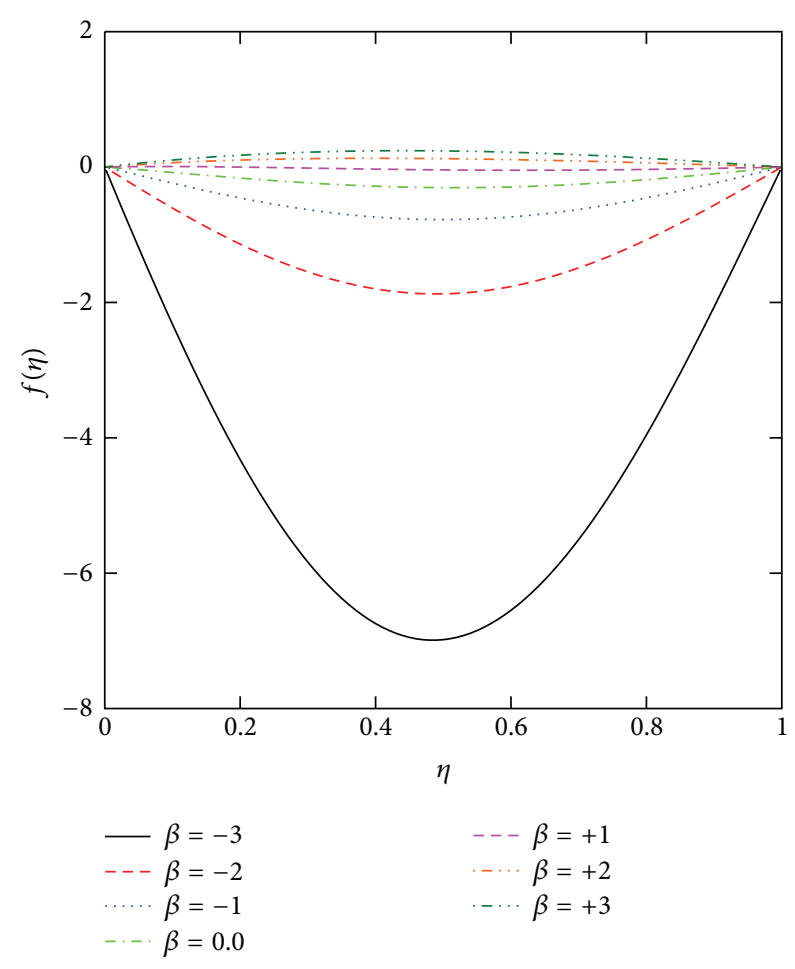

FIGURE 8: Effect of $\beta$ on the velocity component of $g(\eta)$ when $\Omega=1$, $\varphi=0.1$, and $M=w_{0}=0.5$.

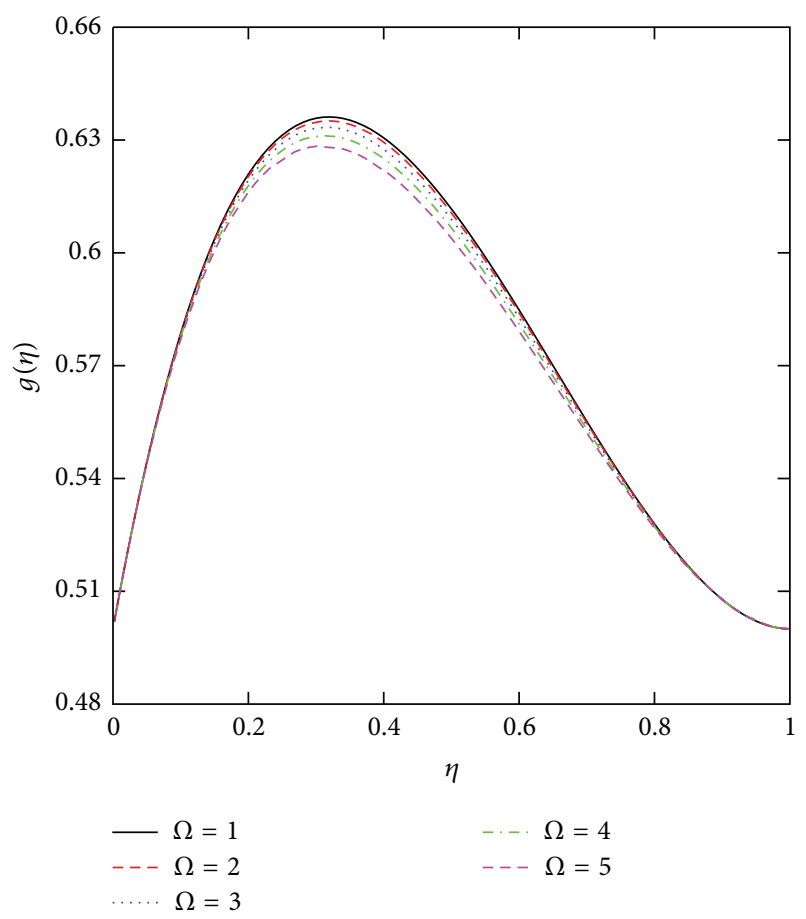

FIGURE 9: Effect of $\Omega$ on the transverse velocity of $f(\eta)$ when $\beta=1$, $\varphi=0.1$, and $M=w_{0}=0.5$. 


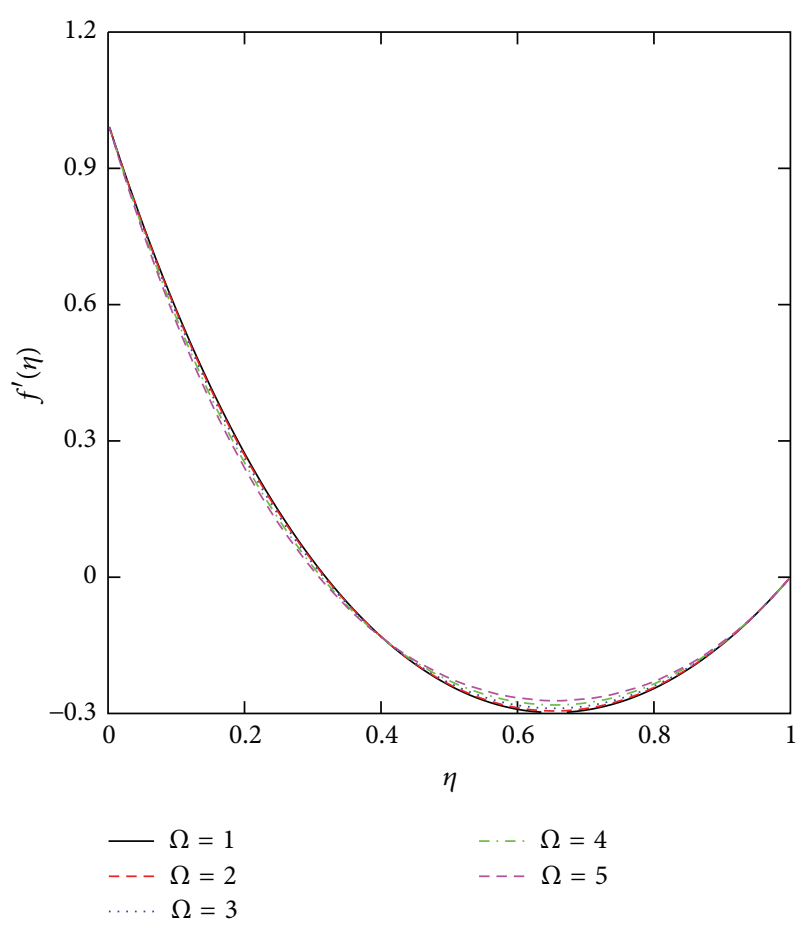

FIGURE 10: Effect of $\Omega$ on the transverse velocity of $f^{\prime}(\eta)$ when $\beta=1$, $\varphi=0.1$, and $M=w_{0}=0.5$.

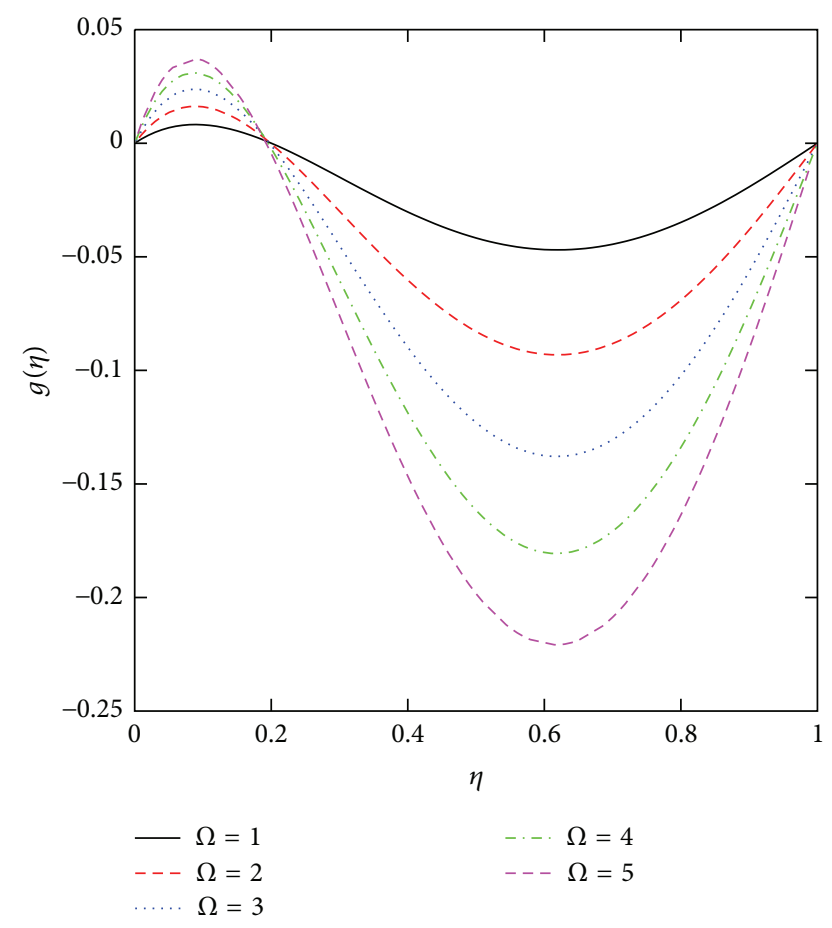

FIGURE 11: Effect of $\Omega$ on the transverse velocity of $g(\eta)$ when $\beta=1$, $\varphi=0.1$, and $M=w_{0}=0.5$.

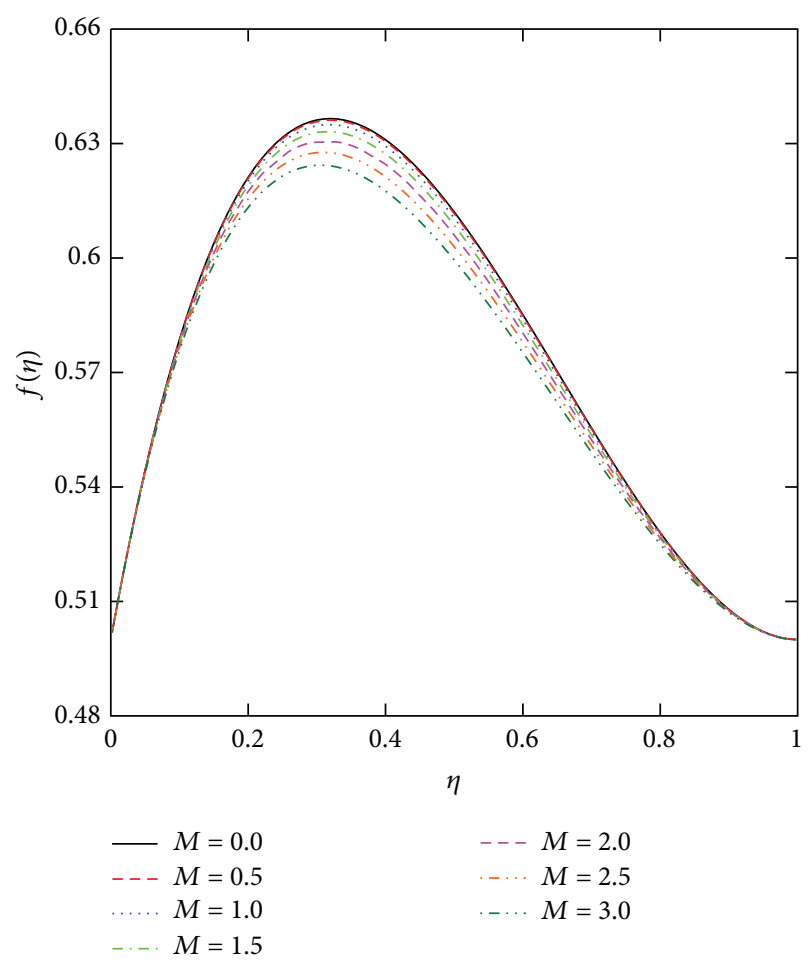

Figure 12: Effect of $M$ on the velocity component of $f(\eta)$ when $\beta=$ $\Omega=1, \varphi=0.1$, and $w_{0}=0.5$.

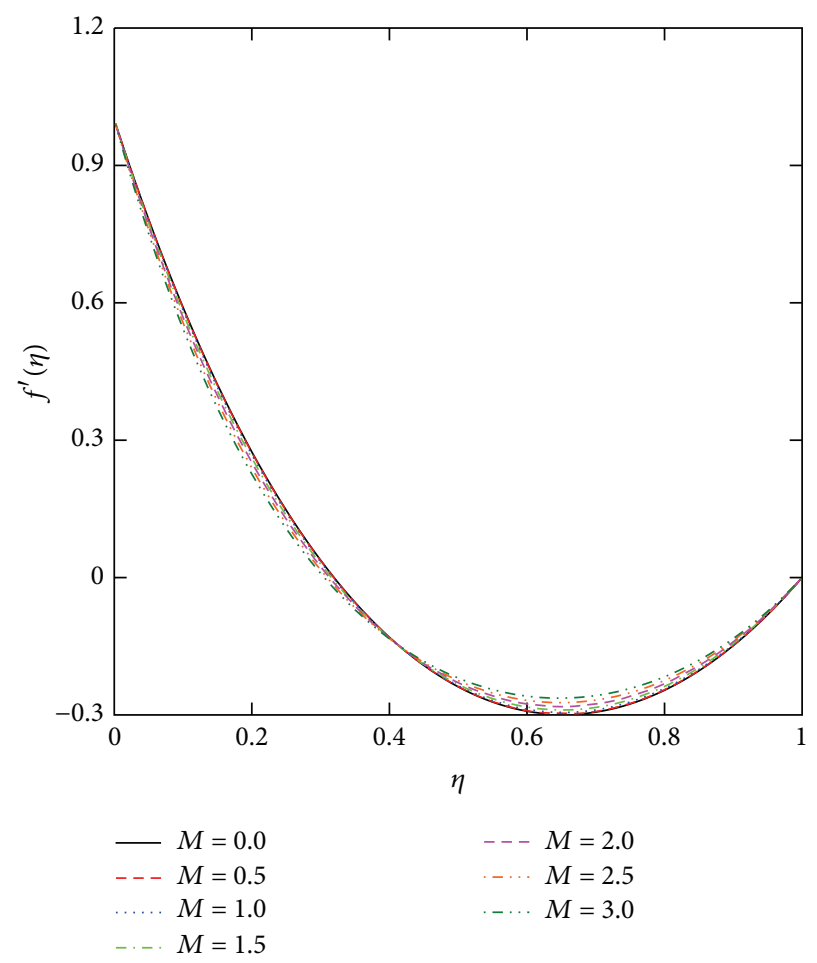

FIgURE 13: Effect of $M$ on the velocity component of $f^{\prime}(\eta)$ when $\beta=\Omega=1, \varphi=0.1$, and $w_{0}=0.5$. 


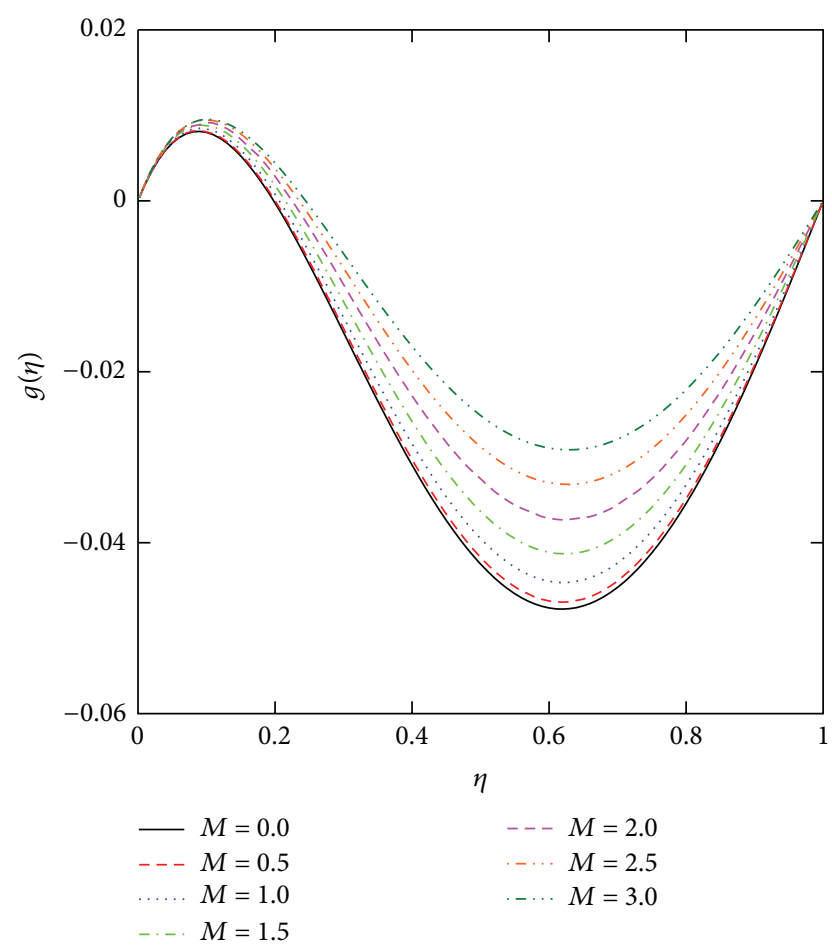

FIGURE 14: Effect of $M$ on the velocity component of $g(\eta)$ when $\beta=$ $\Omega=1, \varphi=0.1$, and $w_{0}=0.5$.

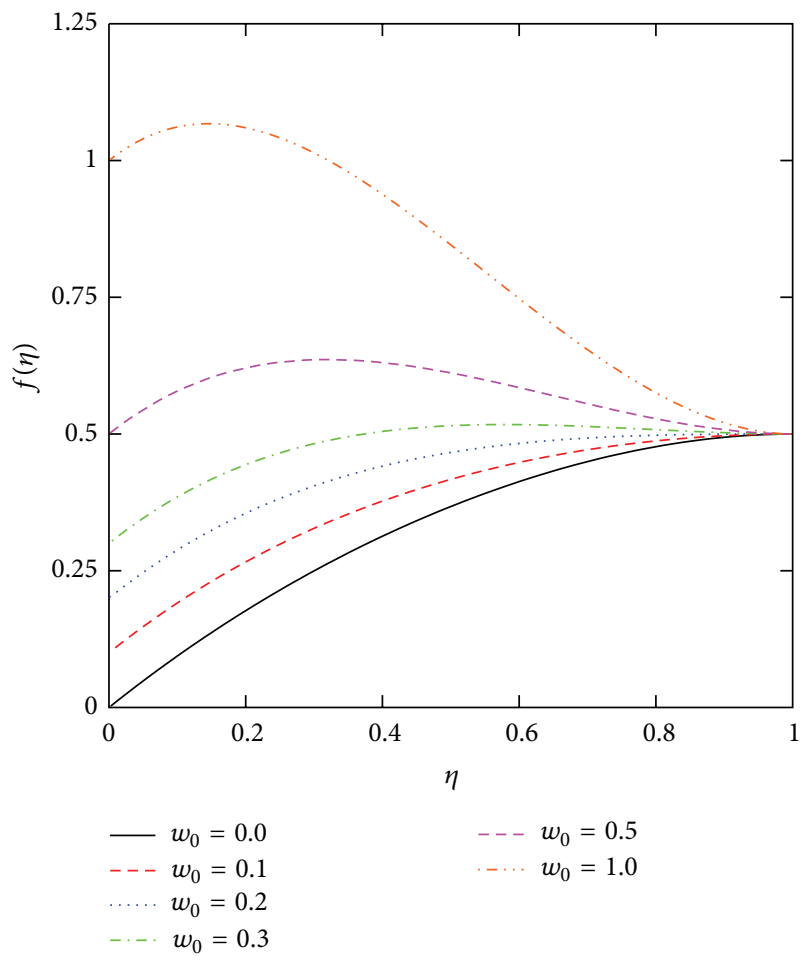

FIGURE 15: Effect of $w_{0}$ on the velocity component of $f(\eta)$ when $\beta=$ $\Omega=1, M=0.5$, and $\varphi=0.1$.

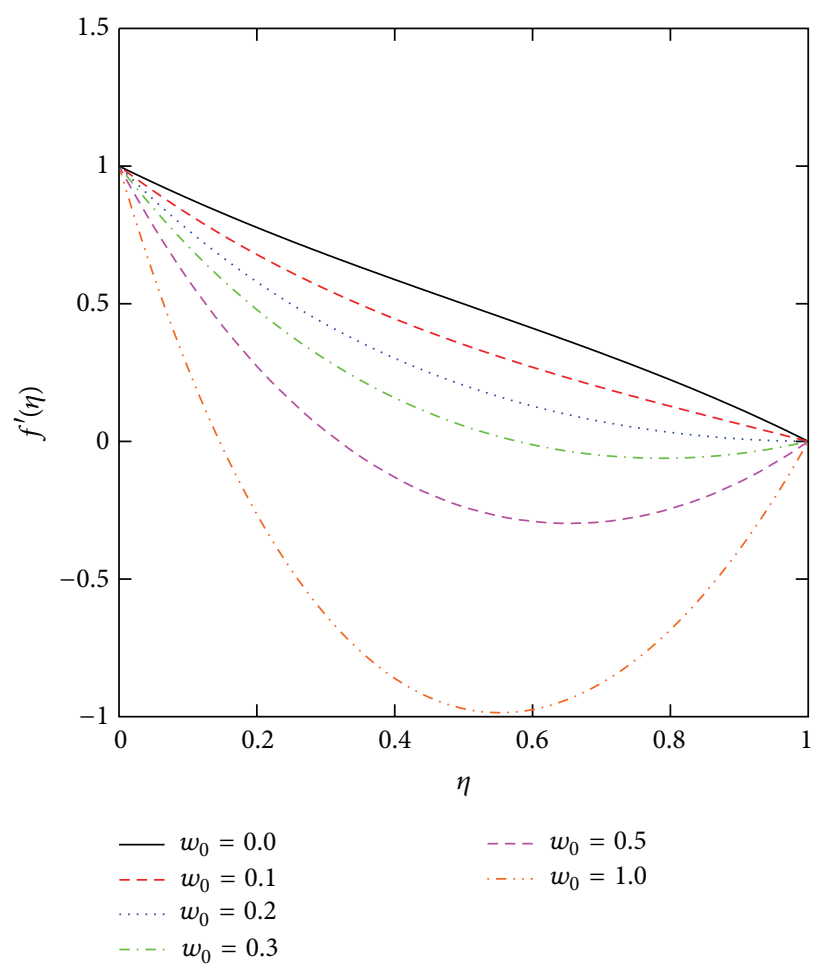

FIGURE 16: Effect of $w_{0}$ on the velocity component of $f^{\prime}(\eta)$ when $\beta=\Omega=1, M=0.5$, and $\varphi=0.1$.

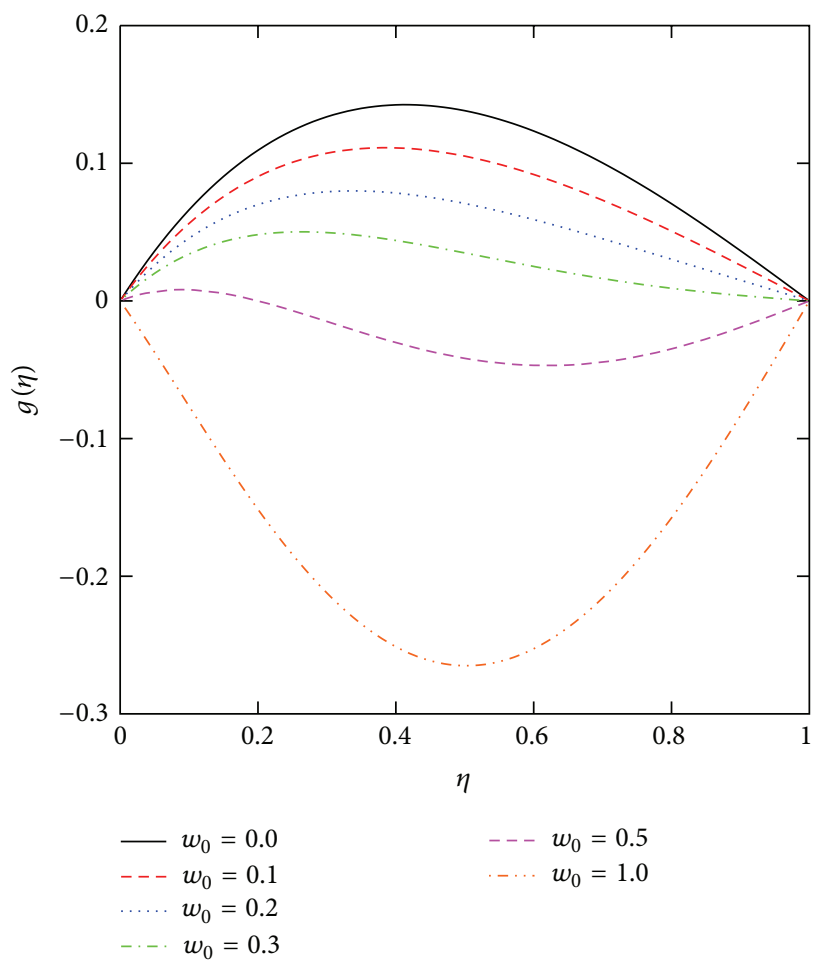

FIGURE 17: Effect of $w_{0}$ on the velocity component of $g(\eta)$ when $\beta=$ $\Omega=1, M=0.5$, and $\varphi=0.1$. 

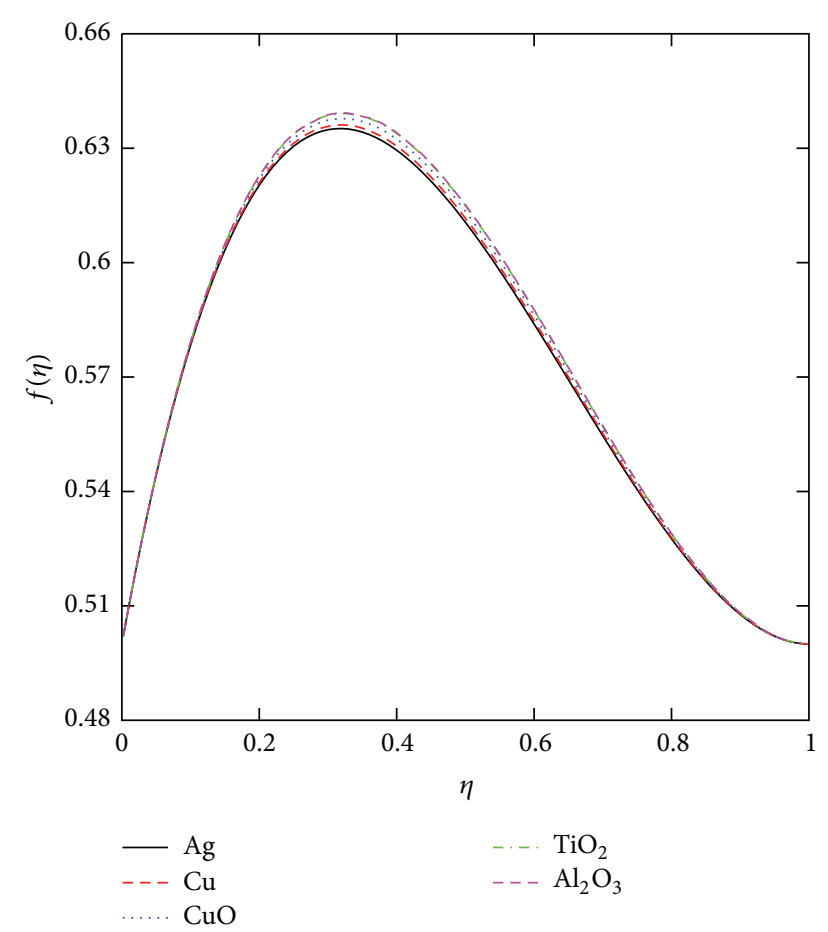

FIGURE 18: Effect of nanoparticle types on the velocity component of $f(\eta)$ when $\beta=\Omega=1, M=w_{0}=0.5$, and $\varphi=0.1$.

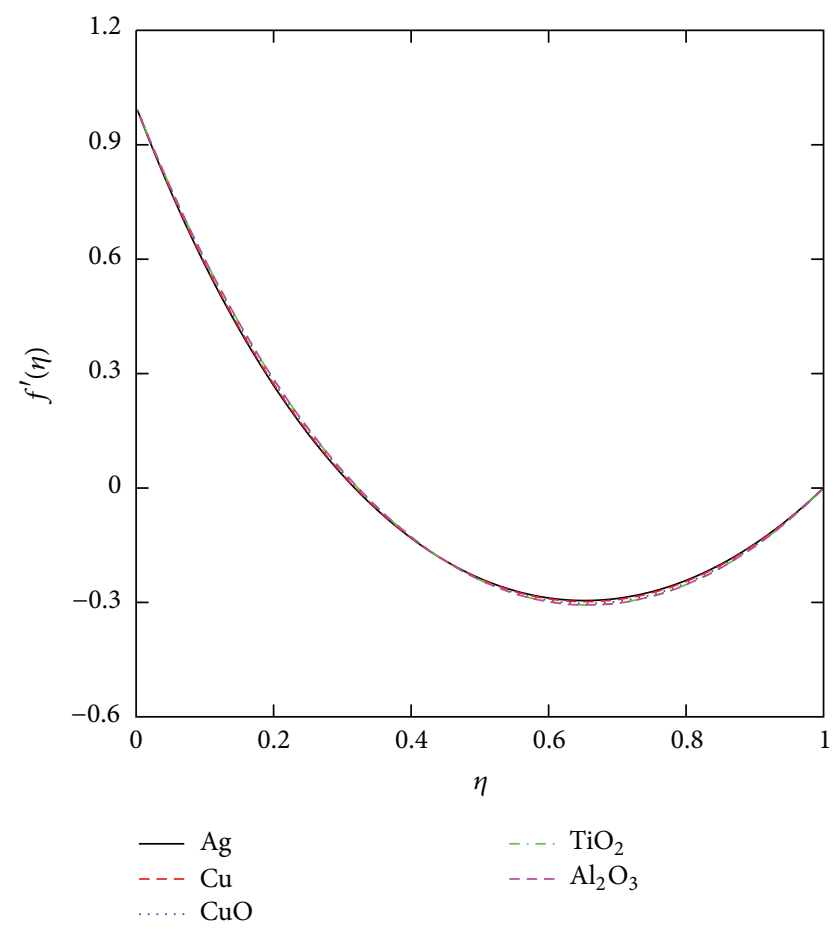

FIGURE 19: Effect of nanoparticle types on the velocity component of $f^{\prime}(\eta)$ when $\beta=\Omega=1, M=w_{0}=0.5$, and $\varphi=0.1$.

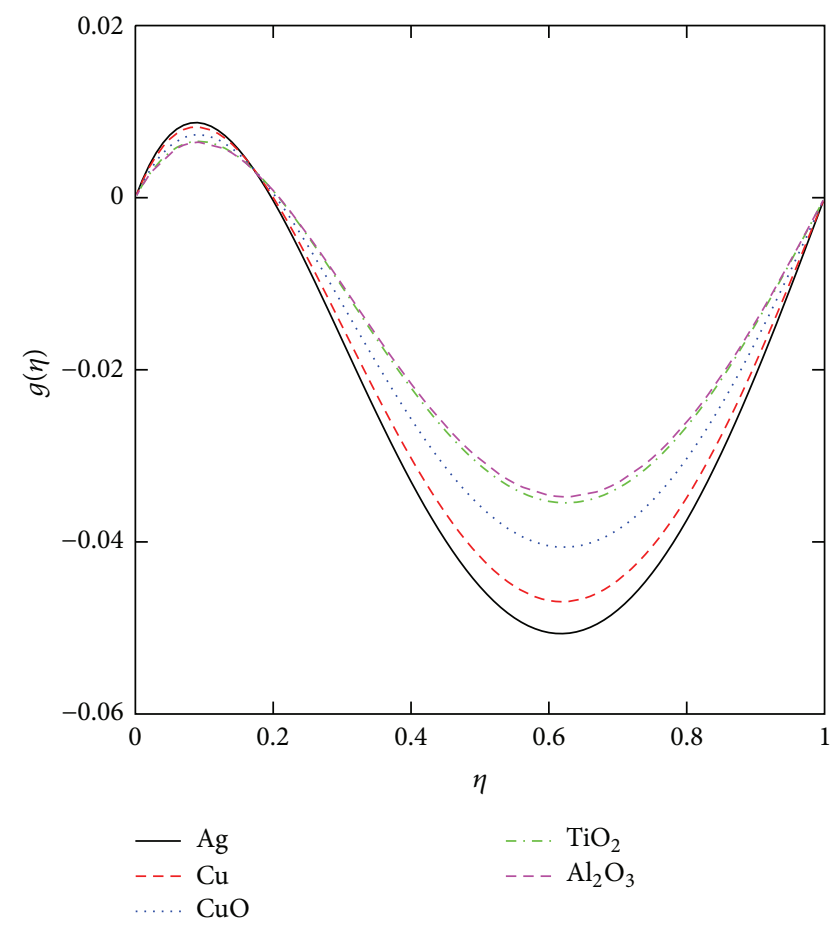

FIGURE 20: Effect of nanoparticle types on the velocity component of $g(\eta)$ when $\beta=\Omega=1, M=w_{0}=0.5$, and $\varphi=0.1$.

\section{Nomenclature}

$a$ : Stretching rate of the lower plate

$B$ : External uniform magnetic field

$B_{0}$ : Constant magnetic flux density

$C_{f}$ : Skin friction coefficient

$f, g$ : Self-similar velocities

$h(t)$ : Upper plane distance

$J: \quad$ Magnetic flux

p: Pressure

$t$ : Time

T: Cauchy stress tensor

$u$ : Velocity component in the $x$ direction

$v$ : Velocity component in the $y$ direction

$w$ : Velocity component in the $z$ direction.

\section{Dimensionless Parameters}

$\beta: \quad$ Characteristic parameter of the flow $(\gamma / a)$

$\Omega: \quad$ Rotation parameter $(\omega / a)$

$M^{2}$ : Magnetic parameter $\left(\sigma B_{0}^{2} / \rho_{f} a\right)$

$w_{0}$ : Suction parameter $\left(V_{0} / a h\right)$

$\operatorname{Re}_{x}$ : Local Reynolds number $\left(\rho_{f} U_{0} h / \mu_{f}\right)$.

\section{Greek Symbols}
$\alpha, \delta$, and $\varepsilon$ : DTM constant parameters
$\sigma: \quad$ Electrical conductivity
$\rho: \quad$ Density 


\author{
$\mu$ : Dynamic viscosity \\ $\eta$ : A scaled boundary-layer coordinate \\ $\nu$ : Kinematic viscosity \\ $\gamma$ : Characteristic constant parameter \\ $\psi$ : Stream function \\ $\omega$ : Constant angular velocity \\ $\varphi$ : Nanoparticle volume fraction.
}

\section{Subscripts}

$$
\begin{array}{ll}
f: & \text { Fluid phase } \\
n f: & \text { Nanofluid } \\
s: & \text { Solid phase. }
\end{array}
$$

\section{Conflict of Interests}

The authors declare that there is no conflict of interests regarding the publication of this paper.

\section{Acknowledgment}

Ebrahim Momoniat acknowledges support from the National Research foundation of South Africa under Grant number 76868.

\section{References}

[1] S. Munawar, A. Mehmood, and A. Ali, "Three-dimensional squeezing flow in a rotating channel of lower stretching porous wall," Computers and Mathematics with Applications, vol. 64, no. 6, pp. 1575-1586, 2012.

[2] B. C. Sakiadis, "Boundary layer behaviour on continuous solid surfaces: I Boundary layer equations for two dimensional and axisymmetric flow," AIChE Journal, vol. 7, pp. 26-28, 1961.

[3] B. C. Sakiadis, "Boundary layer behaviour on continuous solid surfaces: II boundary layer on a continuous flat surface," AIChE Journal, vol. 7, pp. 221-225, 1961.

[4] L. E. Erickson, L. T. Fan, and V. G. Fox, "Heat and mass transfer on a moving continuous flat plate with suction or injection," Industrial and Engineering Chemistry Fundamentals, vol. 5, no. 1, pp. 19-25, 1966.

[5] F. K. Tsou, E. M. Sparrow, and R. J. Goldstein, "Flow and heat transfer in the boundary layer on a continuous moving surface," International Journal of Heat and Mass Transfer, vol. 10, no. 2, pp. 219-235, 1967.

[6] L. J. Crane, "Flow past a stretching plate," Zeitschrift für angewandte Mathematik und Physik ZAMP, vol. 21, no. 4, pp. 645-647, 1970.

[7] H. I. Andersson, "MHD flow of a viscoelastic fluid past a stretching surface," Acta Mechanica, vol. 95, no. 1-4, pp. 227230, 1992.

[8] K. V. Prasad, D. Pal, V. Umesh, and N. S. P. Rao, “The effect of variable viscosity on MHD viscoelastic fluid flow and heat transfer over a stretching sheet," Communications in Nonlinear Science and Numerical Simulation, vol. 15, no. 2, pp. 331-344, 2010.

[9] A. Mehmood and A. Ali, "Analytic solution of generalized three-dimensional flow and heat transfer over a stretching plane wall," International Communications in Heat and Mass Transfer, vol. 33, no. 10, pp. 1243-1252, 2006.

[10] A. Mehmood and A. Ali, "Analytic homotopy solution of generalized three-dimensional channel flow due to uniform stretching of the plate," Acta Mechanica Sinica, vol. 23, no. 5, pp. 503-510, 2007.

[11] A. K. Borkakoti and A. Bharali, "Hydromagnetic flow and heat transfer between two horizontal plates, the lower plate being a stretching sheet," Quarterly of Applied Mathematics, vol. 40, no. 4, pp. 461-467, 1983.

[12] S. Munawar, A. Mehmood, and A. Ali, "Effects of slip on flow between two stretchable disks using optimal homotopy analysis method," Canadian Journal of Applied Science, vol. 1, pp. 50-68, 2011.

[13] A. J. Chamkha, T. Groşan, and I. Pop, "Fully developed free convection of a micropolar fluid in a vertical channel," International Communications in Heat and Mass Transfer, vol. 29, no. 8, pp. 1119-1127, 2002.

[14] R. Bhargava, L. Kumar, and H. S. Takhar, "Numerical solution of free convection MHD micropolar fluid flow between two parallel porous vertical plates," International Journal of Engineering Science, vol. 41, no. 2, pp. 123-136, 2003.

[15] P. D. Ariel, "On exact solutions of flow problems of a second grade fluid through two parallel porous walls," International Journal of Engineering Science, vol. 40, no. 8, pp. 913-941, 2002.

[16] T. Hayat and Z. Abbas, "Channel flow of a Maxwell fluid with chemical reaction," Zeitschrift für angewandte Mathematik und Physik, vol. 59, no. 1, pp. 124-144, 2008.

[17] G. Domairry and A. Aziz, "Approximate analysis of MHD dqueeze flow between two parallel disks with suction or injection by homotopy perturbation method," Mathematical Problems in Engineering, vol. 2009, Article ID 603916, 19 pages, 2009.

[18] S. U. S. Choi and J. A. Eastman, "Enhancing thermal conductivity of fluids with nanoparticles," Materials Science, vol. 231, pp. 99-105, 1995.

[19] Y. Xuan and Q. Li, "Investigation on convective heat transfer and flow features of nanofluids," Journal of Heat Transfer, vol. 125, no. 1, pp. 151-155, 2003.

[20] N. Bachok, A. Ishak, and I. Pop, "Flow and heat transfer over a rotating porous disk in a nanofluid," Physica B: Condensed Matter, vol. 406, no. 9, pp. 1767-1772, 2011.

[21] W. A. Khan and I. Pop, "Boundary-layer flow of a nanofluid past a stretching sheet," International Journal of Heat and Mass Transfer, vol. 53, no. 11-12, pp. 2477-2483, 2010.

[22] M. H. Abolbashari, N. Freidoonimehr, F. Nazari, and M. M. Rashidi, "Entropy analysis for an unsteady MHD flow past a stretching permeable surface in nano-fluid," Powder Technology, vol. 267, pp. 256-267, 2014.

[23] O. A. Beg, M. M. Rashidi, M. Akbari, and A. Hosseini, "Comparative numerical study of single-phase and two-phase models for bio-nanofluid transport phenomena," Journal of Mechanics in Medicine and Biology, vol. 14, Article ID 1450011, 31 pages, 2014.

[24] M. M. Rashidi, A. Hosseini, I. Pop, S. Kumar, and N. Freidoonimehr, "Comparative numerical study of single and two-phase models of nanofluid heat transfer in wavy channel," Applied Mathematics and Mechanics, vol. 35, pp. 831-848, 2014.

[25] E. Abu-Nada, Z. Masoud, H. F. Oztop, and A. Campo, "Effect of nanofluid variable properties on natural convection in enclosures," International Journal of Thermal Sciences, vol. 49, no. 3, pp. 479-491, 2010. 
[26] M. M. Rashidi, S. Abelman, and N. Freidoonimehr, "Entropy generation in steady MHD flow due to a rotating porous disk in a nanofluid," International Journal of Heat and Mass Transfer, vol. 62, no. 1, pp. 515-525, 2013.

[27] M. Mustafa, T. Hayat, I. Pop, S. Asghar, and S. Obaidat, "Stagnation-point flow of a nanofluid towards a stretching sheet," International Journal of Heat and Mass Transfer, vol. 54, no. 25-26, pp. 5588-5594, 2011.

[28] M. M. Rashidi, N. Freidoonimehr, A. Hosseini, O. A. Bég, and T. K. Hung, "Homotopy simulation of nanofluid dynamics from a non-linearly stretching isothermal permeable sheet with transpiration," Meccanica, vol. 49, pp. 469-482, 2014.

[29] M. Sheikholeslami and D. D. Ganji, “Three dimensional heat and mass transfer in a rotating system using nanofluid," Powder Technology, vol. 253, pp. 789-796, 2014.

[30] M. Sheikholeslami, M. Gorji-Bandpy, and D. D. Ganji, "Lattice Boltzmann method for MHD natural convection heat transfer using nanofluid," Powder Technology, vol. 254, pp. 82-93, 2014.

[31] F. Ayaz, "Applications of differential transform method to differential-algebraic equations," Applied Mathematics and Computation, vol. 152, no. 3, pp. 649-657, 2004.

[32] F. Ayaz, "Solutions of the system of differential equations by differential transform method," Applied Mathematics and Computation, vol. 147, no. 2, pp. 547-567, 2004.

[33] M. M. Rashidi and E. Erfani, "A new analytical study of MHD stagnation-point flow in porous media with heat transfer," Computers and Fluids, vol. 40, no. 1, pp. 172-178, 2011.

[34] M. Kurosaka, "The oscillatory boundary layer growth over the top and bottom plates of a rota ting channel," Journal of Fluids Engineering, Transactions of the ASME, vol. 95, no. 1, pp. 68-74, 1973.

[35] H. S. Takhar, A. J. Chamkha, and G. Nath, "MHD flow over a moving plate in a rotating fluid with magnetic field, hall currents and free stream velocity," International Journal of Engineering Science, vol. 40, no. 13, pp. 1511-1527, 2002.

[36] K. Vajravelu and B. V. R. Kumar, "Analytical and numerical solutions of a coupled non-linear system arising in a threedimensional rotating flow," International Journal of Non-Linear Mechanics, vol. 39, no. 1, pp. 13-24, 2004.

[37] G. Domairry and A. Aziz, "Approximate analysis of MHD squeeze flow between two parallel disks with suction or injection by homotopy perturbation method," Mathematical Problems in Engineering, vol. 2009, Article ID 603916, 19 pages, 2009.

[38] H. C. Brinkman, "The viscosity of concentrated suspensions and solutions," The Journal of Chemical Physics, vol. 20, no. 4, p. 571, 1952.

[39] H. F. Oztop and E. Abu-Nada, "Numerical study of natural convection in partially heated rectangular enclosures filled with nanofluids," International Journal of Heat and Fluid Flow, vol. 29, no. 5, pp. 1326-1336, 2008.

[40] M. Sheikholeslami and D. D. Ganji, "Heat transfer of Cu-water nanofluid flow between parallel plates," Powder Technology, vol. 235, pp. 873-879, 2013.

[41] M. M. Rashidi, "The modified differential transform method for solving MHD boundary-layer equations," Computer Physics Communications, vol. 180, no. 11, pp. 2210-2217, 2009.

[42] M. M. Rashidi and N. Freidoonimehr, "Series solutions for the flow in the vicinity of the equator of an MHD boundarylayer over a porous rotating sphere with heat transfer," Thermal Science, vol. 18, pp. S527-S537, 2012. 


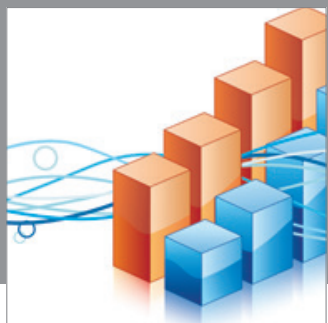

Advances in

Operations Research

mansans

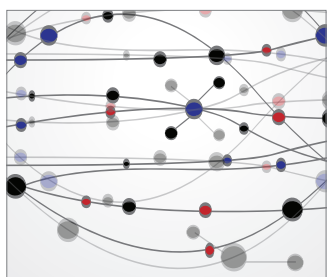

The Scientific World Journal
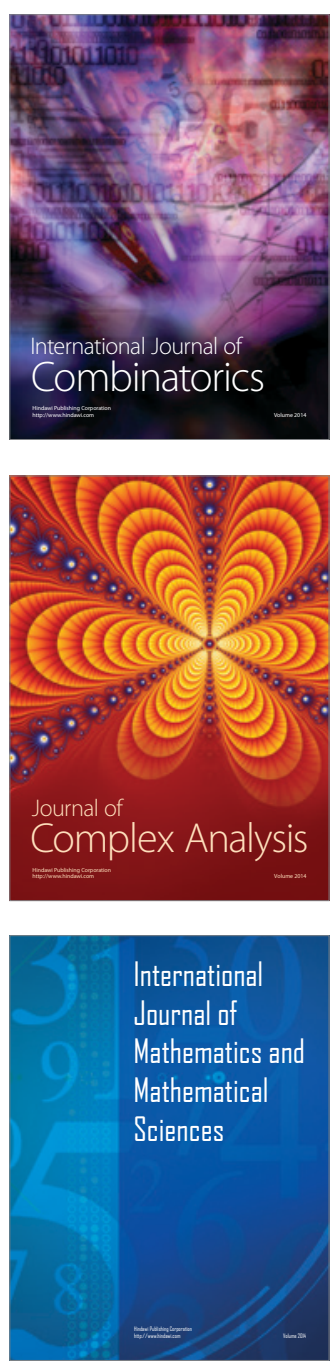
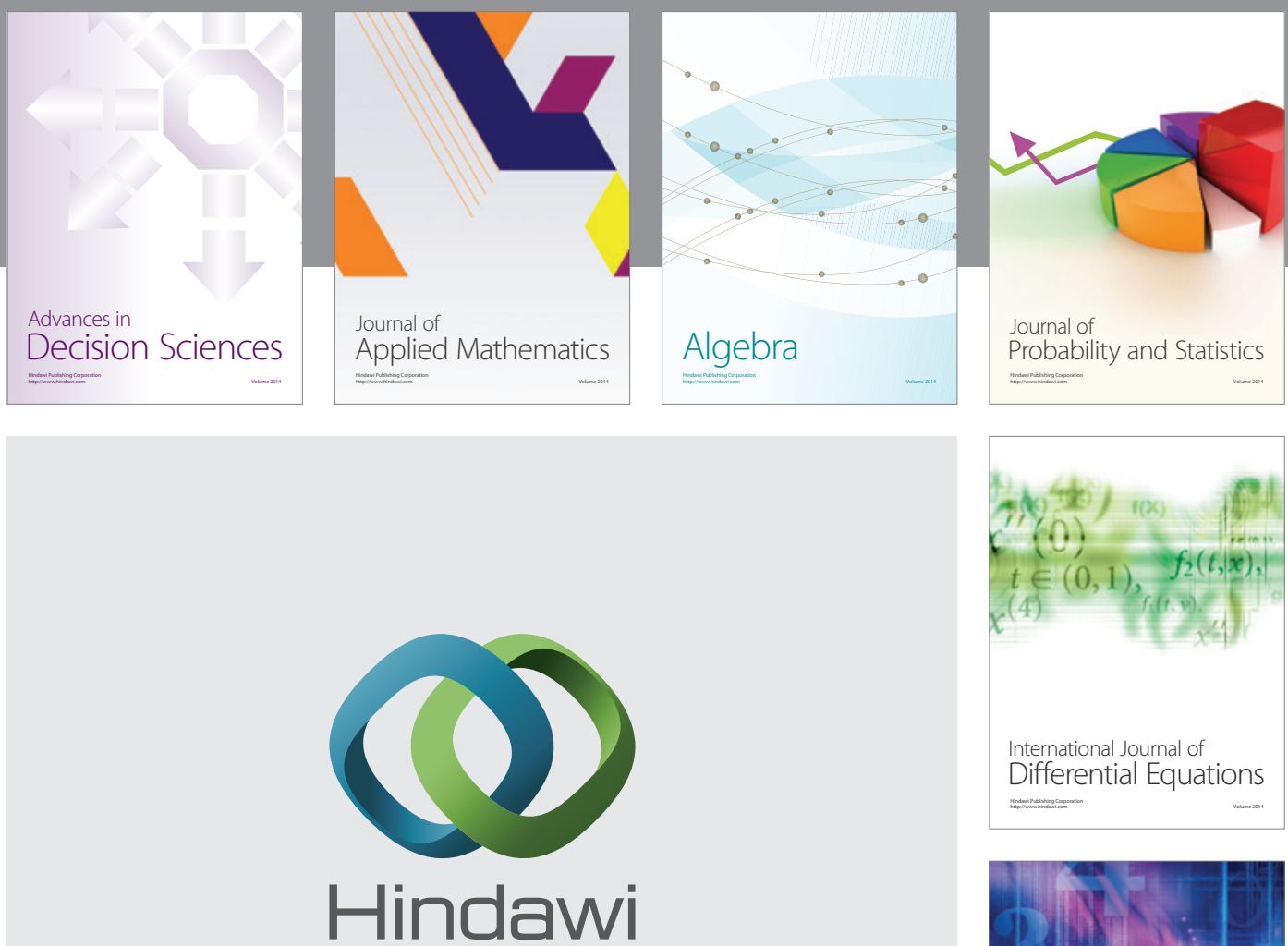

Submit your manuscripts at http://www.hindawi.com
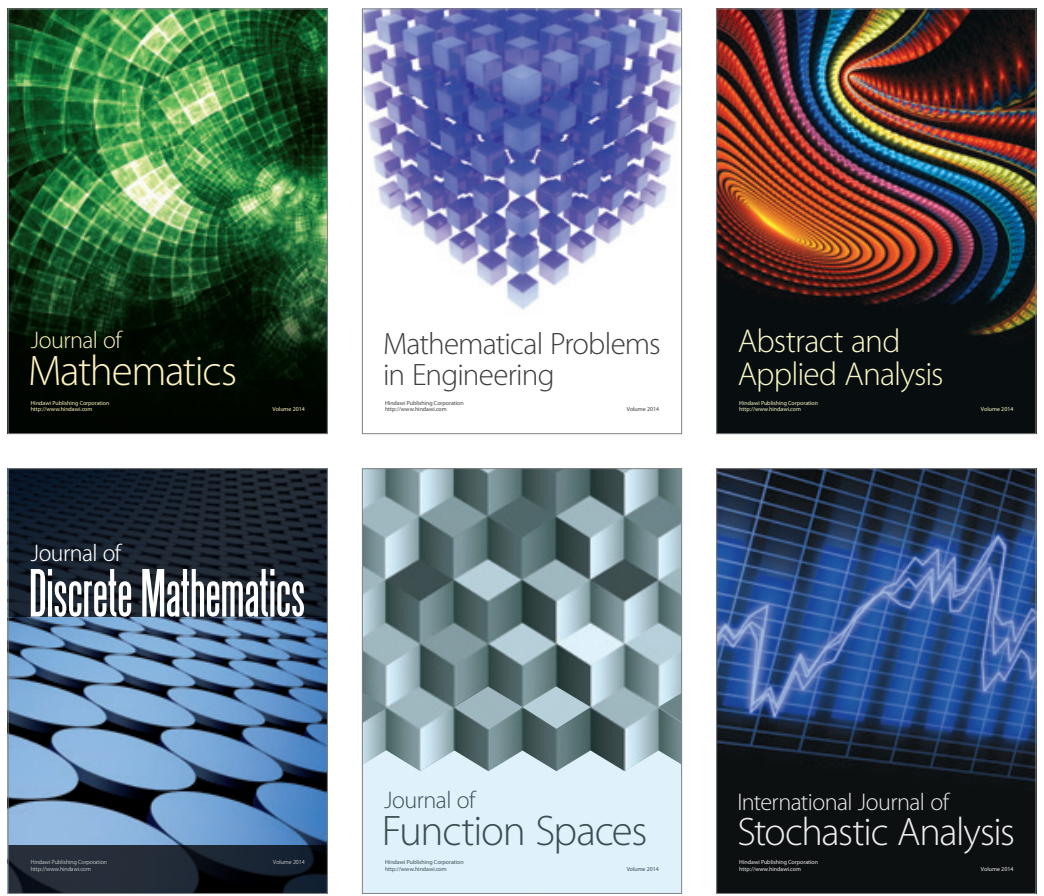

Journal of

Function Spaces

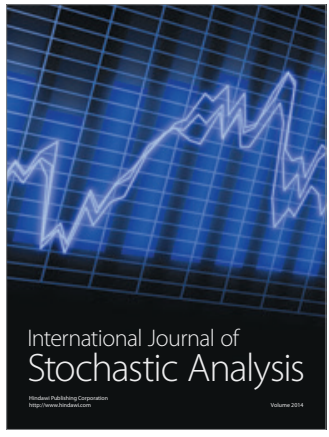

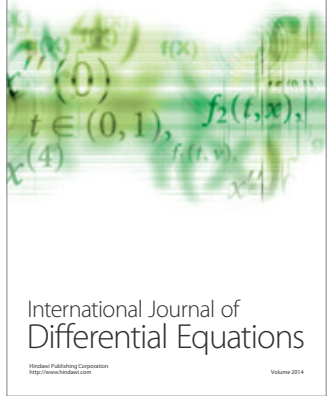
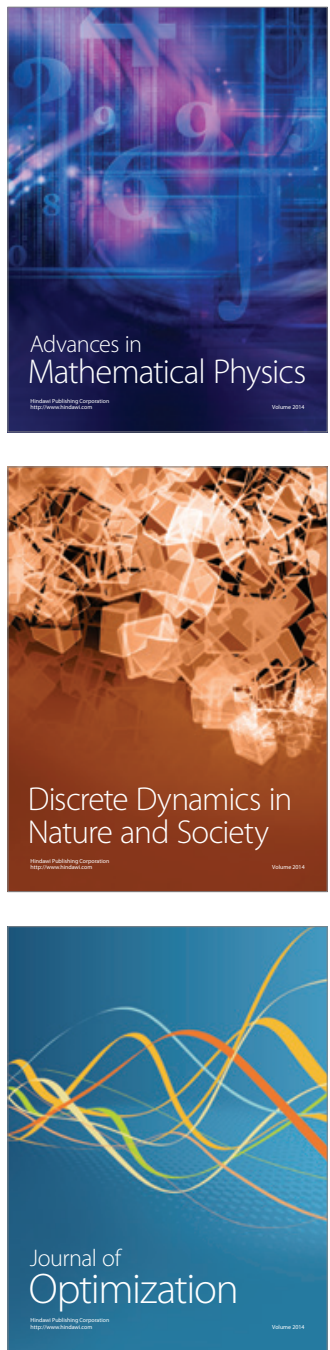